\title{
El triunfo sobre la roca. Selección de ensayos
}

\section{The Triumph over the Rock. \\ Essays Selection}

\author{
Desiderio Navarro
}

Nota preliminar de Consuelo Méndez Tamargo
y Rafael Mondragón Velázquez

Preliminary Note by Consuelo Méndez and Rafael Mondragón

\author{
Universidad Nacional Autónoma de México \\ Instituto de Investigaciones Filológicas \\ consuelomt@unam.mx \\ orcid.org/oooo-ooo3-2452-7985 \\ mondragon.rafael@gmail.com \\ orcid.org/oooo-0003-026o-4476
}

A manera de tributo, incluimos una pequeña muestra de la obra teórica de Desiderio Navarro, publicada en Las causas de las cosas, de 2006 y Ape(n)sar de todo. Para leer en contexto, de 2007. Ambos títulos reúnen una selección de ensayos que habían sido publicados previamente y que reflejan parte del complejo y vasto trabajo investigativo que realizó.

El primero de los ensayos aquí presentados es "In medias res publicas: Sobre los intelectuales y la crítica social en la esfera pública cubana”, lectura imprescindible que invita a una reflexión profunda sobre el papel de la intelectualidad artística en la esfera pública. Como ha señalado Rafael Rojas (2017), este texto de Desiderio Navarro sintetizó la crítica cultural elaborada en los años noventa por ensayistas como Victor Fowler, Arturo Arango, Juan Antonio García Borrero y Norge Espinosa, quienes comenzaron a elaborar una historia de la censura en la isla y a elaborar sugerentes interpretaciones 
sobre las relaciones entre creación artística y poder, todo ello en el marco de un conjunto de luchas culturales que tenían por objeto disputar el significante de la cultura revolucionaria respecto de las interpretaciones restrictivas de ella elaboradas por parte de la burocracia cultural. En el texto antologado, Desiderio Navarro parte de dicha historización para elaborar una sugerente teoría de la censura en cuanto discurso, ideología y concurso de prácticas culturales, que no solo aporta líneas de reflexión fundamentales para pensar en clave crítica la historia reciente de Cuba, sino que también puede ayudar a pensar otros contextos, como es el caso del nuestro. Por cierto, este texto también elabora una sugerente definición sobre lo que sería la crítica y el criterio que puede ayudar a entender por qué el autor le dio ese nombre a su revista.

También de Las causas de las cosas, reproducimos "Unhappy Happening: En torno a un rechazo en la recepción cubana del pensamiento francés sobre la literatura y las artes", que da cuenta del temprano interés de nuestro autor por llevar a la vida cultural de Cuba el pensamiento estético y crítico internacional y de la necesidad de una perspectiva ancha sobre la creación artística. En efecto, se trata de una ponencia de 2002 construida parcialmente a partir de una entrevista inédita de 1967 que Desiderio Navarro habría realizado al principal teórico del happening Alain Jouffroy, y que luego habría entregado a La Gaceta de Cuba para su publicación. Como ocurrió con una inmensa cantidad de textos del autor, el texto fue censurado, por lo que no alcanzó a ser conocido en forma impresa, pero probablemente sí circuló en forma mecanoscrita en algunos de los múltiples círculos intelectuales y artísticos de la isla, cuya vigorosa vida intelectual era sostenida por las intervenciones críticas de Navarro.

¿Qué habría pasado si esa entrevista se hubiera publicado y el arte de la Revolución cubana de 1967 se hubiera encontrado con el happening de los años sesenta? En abierta sintonía con lo que Boaventura de Sousa Santos (2006) ha llamado "sociología de las ausencias", y casi como si se tratara de un texto de ciencia ficción, la ponencia de 2002 se presenta como una arqueología de un texto de 1967 que bien podría ser ficticio y que permite imaginar un pasado distinto al que se tuvo en la isla (y por tanto, un futuro distinto al que comparten el autor y su público), con lo que se produce una peculiar hibridación entre teoría cultural y escritura de ficción que es típica de las intervenciones de Desiderio Navarro y que sería desarrollada con enorme radicalidad en textos como Ella escribía poscrítica, de Margarita Mateo Palmer (1995). Ese encuentro ficticio además ayuda a que el autor entregue una potente lectura comparada de la crisis de la Modernidad en el espacio occidental 
y el espacio cubano: en efecto, el happening comparte con el testimonio y la dramaturgia de creación colectiva una puesta en crisis de la figura del autor, así como de sus procedimientos de autoridad y autorización, además de participar de un ambiente de época que busca construir una conciencia de lo colectivo, al tiempo que está preso de un devenir que puede dar pie al fortalecimiento de formas autoritarias de autoridad política.

Por último, incluimos "El paisaje: problemas teóricos del género", publicado en el libro Ape(n)sar de todo. Para leer en contexto, en el que se problematizan concepciones ortodoxas dominantes en el campo del paisaje, particularmente el pictórico. Este denso ensayo constituye una muestra del trabajo práctico de Desiderio Navarro en el momento de abordar el análisis preciso de una categoría. De Alfonso Reyes a José Lezama Lima, el paisaje es una categoría fundamental en el ensayo latinoamericano de los siglos XIX y Xx. A través de su elucidación de cómo funciona el género paisajístico en la pintura, Navarro se inserta a sí mismo en dicha tradición, a la que enriquece por medio de una rica selección de textos teóricos que ponen en diálogo intercultural teorías de la pintura de Cuba, China y Europa (la Europa más conocida y también la Europa periférica, que es la que Desiderio Navarro siempre prefirió para entablar diálogos que permitieran pensar mejor la experiencia latinoamericana).

La constelación de textos construida por Navarro en este ensayo además elabora una teoría de la Modernidad en cuanto cambio histórico de las formas de experiencia, y prefigura la posibilidad de una semiótica del arte y la cultura enriquecida por los aportes de la teoría literaria, la sociología del arte y la iconografía. Como siempre ocurre en los textos de este autor, la construcción de categorías teóricas y el análisis del pasado es, en realidad, una intervención que quiere iluminar el presente: lo que importa en el fondo es el intento de pensar críticamente el tipo de cambio en la experiencia introducido por la Revolución cubana y la manera en que él pervive en el presente más inmediato, así como la manera en que él puede ser pensado a través de las obras de arte, que no son meras ilustraciones del mismo, sino reconstrucciones críticas de su sentido.

En el momento de editar los tres ensayos hemos aprovechado para corregir dos erratas menores. Contraviniendo en esta ocasión las normas editoriales de Interpretatio, hemos respetado la forma original de citar presente en los textos, pues nos pareció que la construcción del aparato de notas al pie aportaba elementos fundamentales en la forma de argumentación de nuestro autor. 


\section{Bibliografía}

Mateo Palmer, Margarita (1995). Ella escribía poscrítica. La Habana, Casa Editora Abril.

RojAs, Rafael (2017). "Breve historia de la censura en Cuba (1959-2016), La Razón, 28 de enero de 2017 , <https://www.razon.com.mx/el-cultural/breve-historia-dela-censura-en-cuba-1959-2016/>, consultado por última vez el 16 de noviembre de 2020.

DE Sousa SANTOS, Boaventura (2006). "La sociología de las ausencias y la sociología de las emergencias: para una ecología de saberes”, en Reinventar la teoría crítica y reinventar la emancipación social. Encuentros en Buenos Aires. Buenos Aires, Clacso.

\section{Consuelo Méndez Tamargo}

Maestra en Lingüística Aplicada y licenciada en Periodismo y Ciencias de la Comunicación por la Universidad Nacional Autónoma de México. Obtuvo la especialidad académica en televisión educativa del Institut National de L’Audiovisuel, en Bry sur Marne, Francia. Sus líneas de investigación incluyen la hermenéutica literaria y la hermenéutica de las artes, especialmente enfocadas en la adaptación literaria al cine. Recientemente coordinó la edición y compilación del libro Miradas semióticas, publicado por el CELE-UnAM. Editora del dossier Hermenéutica del cine en Interpretatio. Revista de Hermenéutica, 3-2, sep. 2018-feb. 2019. Ha participado en numerosos foros académicos nacionales e internacionales. Actualmente es académica de tiempo completo del Seminario de Hermenéutica del Instituto de Investigaciones Filológicas de la UNAM.

\section{Rafael Mondragón Velázquez}

Doctor en Letras por la Universidad Nacional Autónoma de México, en cuya Facultad de Filosofía y Letras es profesor. Pertenece al Sistema Nacional de Investigadores (Nivel I). Es Investigador del Seminario de Hermenéutica del Instituto de Investigaciones Filológicas y colaborador regular en círculos de lectura, talleres de educación popular y experiencias de trabajo cultural comunitario. Junto a María del Rayo Ramírez Fierro y Freja Cervantes coordinó la edición facsimilar, documentada y anotada de Sociedades americanas en 1828, de Simón Rodríguez (6 vols., México, UAM-I, 2018). Es autor de Filosofía y narración. Escolio a tres textos del exilio argentino de Francisco Bilbao (2015), de La escuela como espacio de utopía. Algunas propuestas de la tradición anarquista (2018) y de Un arte radical de la lectura. Constelaciones de la filología latinoamericana (2019). 


\section{In medias res publicas: Sobre los intelectuales y la crítica social en la esfera pública cubana ${ }^{1}$}

En medio de la cosa pública: es ahí donde están llamados los intelectuales a desempeñar su papel en cada país. Pero, como bien señala el documento del Prince Claus Fund que nos convoca, "en varios aspectos el papel de los intelectuales difiere de país en país”, y también los “constreñimientos materiales, culturales y políticos" que ellos experimentan "difieren de situación en situación". Es preciso tener en cuenta esas diferencias si no se quiere correr el riesgo de incurrir en extrapolaciones ilícitas, generalizaciones infundadas y etnocentrismos. En efecto, como añade el documento: "Hay necesidad de entender el papel de los intelectuales en esos contextos y discutir los dilemas clave".

Las observaciones y reflexiones que siguen se proponen contribuir a la comprensión del papel de la intelectualidad artística en la esfera pública en la Cuba revolucionaria, esto es, en los últimos cuarenta años de historia de mi país. Se trata de un período muy largo y complejo que sería imposible presentar y analizar debidamente en el estrecho marco prestablecido de esta ponencia. De ahí el carácter abocetado y la ejemplificación mínima de la siguiente introducción histórica, realizada según el criterio de la pertinencia al problema que aquí nos ocupa.

En junio de 1961, en una célebre reunión con las personalidades más representativas de la intelectualidad cubana de entonces, el Comandante Fidel Castro formuló una frase que, por su brevedad, construcción y categoricidad, funcionó, desde entonces hasta la fecha, como el resumen de la política cultural de la Revolución: "dentro de la Revolución, todo; contra la Revolución,

1 Ponencia presentada en la Conferencia Internacional "El papel del intelectual en la esfera pública”, organizada por el Fondo del Príncipe Claus de Holanda, y celebrada en Beirut, del 24 al 25 de febrero del 2000. Ha sido publicada en: La Gaceta de Cuba, La Habana, 2001, núm. 3, pp. 40-45; Ensayo cubano del siglo XX, selec., pról. y notas de Rafael Hernández y Rafael Rojas, Fondo de Cultura Económica, México, 2002, pp. 689-707, y Revista del CESLA, núm. 4, Centro de Estudios Latinoamericanos, Universidad de Varsovia, Varsovia, 2002, pp. 111-123. En traducción al inglés, apareció en: Nepantla: Views from the South, Duke University (EUA), 2001, vol. 2, núm. 2, pp. 355-371, y boundary 2, Duke University Press (EUA), 2002, vol. 29, núm. 3 (special issue From Cuba), pp. 187-203. La presente versión fue publicada en: Desiderio Navarro (2006), Las causas de las cosas. La Habana, Editorial Letras Cubanas: 7-31.

2 The role of the intellectual in the public sphere, Beirut, Lebanon, 24, 25 February 20oo: Reader, Prince Claus Fund, The Hague, Holanda, p. 3. 
nada".3 Sacado de su contexto y en manos de toda clase de hermeneutas y exégetas circunstanciales, ese versículo de las que en adelante serían conocidas como "Palabras a los intelectuales" daría muestras de una extraordinaria polisemia que le permitiría ser el principio rector reconocido por los sucesivos períodos y tendencias en lucha. 4

La vida cultural y social del país pondría una y otra vez sobre el tapete muchas preguntas más concretas que quedaron sin una respuesta amplia, clara y categórica: ¿Qué fenómenos y procesos de la realidad cultural y social cubana forman parte de la Revolución y cuáles no? ¿Cómo distinguir qué obra o comportamiento cultural actúa contra la Revolución, qué a favor y qué simplemente no la afecta? ¿Qué crítica social es revolucionaria y cuál es contrarrevolucionaria? ¿Quién, cómo y según qué criterios decide cuál es la respuesta correcta a esas preguntas? ¿No ir contra la Revolución implica silenciar los males sociales que sobreviven del pasado prerrevolucionario o los que nacen de las decisiones políticas erróneas y los problemas no resueltos del presente y el pasado revolucionarios? ¿Ir a favor de la Revolución no implica revelar, criticar y combatir públicamente esos males y errores? Y así sucesivamente.

Después del triunfo revolucionario de 1959, y sobre todo después de la declaración del carácter socialista de la revolución en abril de 1961, las relaciones entre la vanguardia política y la vanguardia intelectual o artística - para emplear las denominaciones en curso por entonces- conocieron tensiones fuertes, pero puntuales o pasajeras, en materia de política cultural (por ejemplo, en relación con la prohibición de la exhibición pública del filme "P.M." de Sabá Cabrera Infante en 1961 o con el "sectarismo" de 1961-1962); sin embargo, puede hablarse de una amplia adhesión de la segunda a las decisiones y proyecciones de la primera en las demás esferas de la vida política nacional. Por

3 Fidel Castro: Palabras a los intelectuales, Ediciones del Consejo Nacional de Cultura, La Habana, 1961, p. 11.

4 En octubre de 1977, en su discurso de clausura del Segundo Congreso de la Unión de Escritores y Artistas de Cuba (desde el primer congreso habían pasado ya dieciséis años), Armando Hart, entonces Ministro de Cultura, observaba lo siguiente: "Las deficiencias, dificultades y los logros que han existido durante el período comprendido entre el Primer y el Segundo Congresos de la UNEAC, están en parte relacionados con la mayor o menos comprensión que cada cual ha tenido de la esencia más profunda de las palabras de Fidel cuando, en pensamiento que todo lo sintetiza, proclamó: 'Dentro de la revolución todo, contra la Revolución nada', o cuando dijo: 'El arte es un arma de la Revolución”” (Armando Hart: Del trabajo cultural. Selección de discursos, Editorial de Ciencias Sociales, La Habana, 1978, p. 142). 
otra parte, todavía en septiembre de 1966, en un artículo titulado "Hacia una intelectualidad revolucionaria en Cuba”, Roberto Fernández Retamar, uno de los más destacados pensadores de aquella vanguardia intelectual, podía presentar la crítica de los errores de los políticos como un deber consustancial a la adhesión del intelectual a la Revolución y como un factor de diagnóstico y corrección tomado en cuenta por los políticos cubanos "realmente existentes" por entonces:

Un error teórico cometido por quien puede convertir sus opiniones en decisiones, ya no es sólo un error teórico: es una posible medida incorrecta. Con medidas incorrectas hemos topado, y ellas plantean, por lo pronto, un problema de conciencia a un intelectual revolucionario, que no lo será de veras cuando aplauda, a sabiendas de que lo es, un error de su revolución, sino cuando haga ver que se trata de un error. Su adhesión, si de veras quiere ser útil, no puede ser sino una adhesión crítica, puesto que la crítica es "el ejercicio del criterio". Cuando hemos detectado tales errores de la revolución, los hemos discutido. Así ha pasado no sólo en el orden estético, sino con equivocadas concepciones éticas que se han traducido en medidas infelices. Tales medidas fueron rectificadas, unas, y otras están en vías de serlo. Y ello, en alguna forma, por nuestra participación. [...] de alguna manera, por humilde que sea, contribuimos a modificar ese proceso [la revolución]. De alguna manera somos la revolución. 5

Frente a la socorrida hipostasiación de la sinécdoque que hace de un dirigente individual o de un colectivo de ellos a tal o cual nivel, "la Revolución", y de sus ideas y decisiones, por carácter transitivo, las ideas y decisiones de "la Revolución”, Fernández Retamar recordaba que también los intelectuales revolucionarios son una parte en el todo de esa Gran Sinécdoque.

Para la mayoría de los intelectuales revolucionarios - pero no para la mayoría de los políticos - estaba claro que su papel en la esfera pública debía ser el de una participación crítica. Alrededor de 1968 se hace sentir con cierta fuerza en esa esfera la intervención crítica intelectual desde diversas posiciones políticas: el relativo monologismo dominante ya por varios años sobre la base de la coincidencia política espontánea y de cierta medida de autocensura en consideración al peligro de la manipulación informativa enemiga, es roto por voces intelectuales aisladas que emprenden cuestiona-

5 “Hacia una intelectualidad revolucionaria en Cuba”, en R. Fernández Retamar: Ensayo de otro mundo, Instituto del Libro, La Habana, Cuba, 1967, p. 186. 
mientos puntuales o amplios del proceso revolucionario, o incluso impugnaciones globales.

Esa heteroglosia en cuestiones políticas resultaba tanto más resonante cuanto que se presentaba sobre el fondo de una intelectualidad nacional prorevolucionaria que, por paradójico que parezca, no intervenía públicamente en discusiones extraestéticas. Al enumerar "algunos problemas del intelectual revolucionario" en el artículo antes citado, Fernández Retamar había mencionado en primer lugar precisamente ese extraño silencio:

Hace poco me preguntaba en México Víctor Flores Olea por qué los intelectuales cubanos no participaban sino excepcionalmente en las discusiones sobre problemas de tanto interés como las referidas al estímulo material y al estímulo moral, a la ley del valor, etcétera, asuntos que solían ser tratados por el Che, Dorticós y otros [...]. La pregunta [...], entre otras cosas, roza este punto: los intelectuales cubanos, que han debatido lúcidamente sobre cuestiones estéticas, deben considerar otros aspectos, so pena de quedar confinados en límites gremiales. ${ }^{6}$

Y había reclamado "esa ampliación de la problemática intelectual" justamente como parte del "proceso de conversión en intelectuales de la revolución".7

Por otro lado, también en las relaciones con la intelectualidad extranjera se puso de manifiesto una heteroglosia política análoga: gran parte de la intelectualidad extranjera izquierdista o progresista (fundamentalmente europea y latinoamericana) reaccionó con críticas al Gobierno Revolucionario en relación con la aprobación de la invasión de Checoslovaquia por las tropas del Pacto de Varsovia en 1968 y con el arresto y detención del poeta cubano Heberto Padilla en 1971. Si en enero de 1968, en ocasión del Congreso Cultural de La Habana, se ensalzaba a los trabajadores intelectuales del mundo y de Europa en particular precisamente por intervenir en la esfera pública con protestas y combativas movilizaciones en favor de causas como la de Cuba durante la Crisis de Octubre, la guerrilla del Che, la lucha de Vietnam, el movimiento negro en EUA, etcétera, en contraste con el nulo o escaso apoyo público de las vanguardias, organizaciones y partidos revolucionarios mundiales, ya en 1971 se descubre entre ellos una "maffia" de "falsos intelectuales", "pequeñoburgueses seudoizquierdistas del mundo capitalista que utilizaron la Revolución

7 Ob. cit., p. 179. 
como trampolín para ganar prestigio ante los pueblos subdesarrollados", y que "intentaron penetrarnos con sus ideas reblandecientes, imponer sus modas y sus gustos e, incluso, actuar como jueces de la Revolución". ${ }^{8}$

De repente, para la mayoría de los políticos, el intelectual apareció como un Otro ideológico real que los interpela en el espacio público sobre asuntos nacionales extraculturales, políticos. Esa aparición, así como el conocimiento del papel desempeñado por los intelectuales checos en la por entonces reciente Primavera de Praga, la creciente influencia del modelo socio-político y cultural soviético en su etapa de Restauración brezhneviana, son algunos de los factores que contribuirían a que muchos políticos llegaran a ver en la intelectualidad como tal un compañero de ruta no confiable, e incluso una potencial fuerza política opositora. Algunos no dejaron de aprovechar la idea expuesta por el Che Guevara en El socialismo y el hombre en Cuba (1965) de que "la culpabilidad de muchos de nuestros intelectuales y artistas reside en su pecado original; no son auténticamente revolucionarios", al tiempo que hicieron caso omiso de un mandamiento político formulado por el propio Che a continuación en el mismo párrafo: "No debemos crear asalariados dóciles al pensamiento oficial ni 'becarios' que vivan al amparo del presupuesto, ejerciendo una libertad entre comillas". 9

De 1968 en adelante, más allá de una serie de medidas administrativas (la más simbólica de todas sería la disolución de la importante revista llamada precisamente Pensamiento Crítico), se produjo una verdadera cruzada contra la intervención crítica de la intelectualidad en la esfera pública, cruzada que tuvo su punto culminante en el Primer Congreso Nacional de Educación y Cultura (1971) y que sólo vino a desarticularse a principios de los años 80 con el fracaso del último desesperado intento de implantar como doctrina oficial el realismo socialista en su versión soviética más hostil a la crítica social. Justamente a principios de los 8 o comienzan a oírse nuevamente voces críticas, esta vez con más fuerza y en mayor número, pertenecientes a jóvenes intelectuales nacidos y formados ya dentro de la Revolución - en su gran mayoría artistas plásticos, pero también narradores, teatristas, cineastas y ensayistas.

Nadie ha descrito mejor que el crítico de arte cubano Gerardo Mosquera cómo concebían y desempeñaban aquellos jóvenes artistas plásticos el papel

8 “Declaración del Primer Congreso Nacional de Educación y Cultura”, en Casa de las Américas, La Habana, núm. 65-66, p. 17.

9 Ernesto Che Guevara: El socialismo y el hombre en Cuba, Ediciones R, La Habana, 1965, p. 49. 
del intelectual en la esfera pública: "Se siente [en ellos] una gran urgencia por ir 'más allá del arte' para abordar con él en directo los problemas de la sociedad, sin hacer la más mínima concesión artística." Añadía que esos artistas estaban "llevando adelante un cuestionamiento crítico muy serio de problemas de nuestra realidad que, aunque se tocan en los pasillos, de rareza han traspasado la oralidad para discutirse públicamente con todas sus letras." Y en una clara relación intertextual con la mencionada frase de Fidel, concluía: "Por fuerte que resulte en su expresión, se trata de un cuestionamiento dentro del socialismo y por el socialismo". ${ }^{\circ}$

Todavía a mediados de 1989 Mosquera podía señalar: "Las artes plásticas [...] constituyen ahora la tribuna más osada. Su crítica social analiza males muy reales en busca de la rectificación." Y menciona algunos de esos males: "burocracia, oportunismo, autoritarismo, rectificación pero no mucha, pancismo, centralismo antidemocrático...."

En relación con esa voluntad de crítica y discusión públicas se produjo en los 8 o una proliferación inaudita de espacios culturales de todo tipo: espacios de exhibición, de publicación, de lectura, de discusión; espacios institucionales y no institucionales; espacios privados y espacios públicos. Una inusitada característica de muchos de esos nuevos espacios fue la apertura a la intervención espontánea no revisada, autorizada y programada previamente (por ejemplo, la lectura pública de textos no sometidos con días o semanas de anticipación a diversas instancias culturales y políticas para su aprobación, corrección o rechazo).

Por otra parte, esa actividad intelectual crítica se caracterizó por una orientación, nunca antes vista, hacia lo no institucional y lo antiinstitucional. Frente a los constreñimientos de los espacios institucionales y sus usos institucionales, desarrolló las siguientes estrategias:

- irrupción imprevista y apropiación efímera, "desconstructiva”, de espacios culturales institucionales (repentinos performances no programados en medio de vernissages o conferencias ajenas);

- creación de espacios culturales no institucionales (exhibiciones de obras plásticas y representaciones teatrales en casas particulares, un

10 Gerardo Mosquera: “Crítica y consignas", La Gaceta de Cuba, La Habana, noviembre de 1988, p. 26.

11 Gerardo Mosquera: “Trece criterios sobre el nuevo arte cubano”, La Gaceta de Cuba, junio de 1989, p. 24. 
periódico cultural samizdat), algunos de los cuales tenderían a devenir una especie de instituciones no institucionales (galerías en casas o en un céntrico parque);

- irrupción y apropiación más o menos efímera de espacios públicos (graffiti, murales y performances en las calles de la ciudad, un juego de base-ball por artistas y críticos en un estadio de base-ball).

Pero ya desde 1988 se produce nuevamente una ofensiva contra la intervención crítica del intelectual en la esfera pública, que - por obra del desencanto, el pesimismo, el escepticismo, y hasta el amargo resentimiento que genera, y en conjunción con las duras condiciones de trabajo y de vida creadas por la crisis económica de principios de los 90, y la simultánea apertura en la concesión de permisos de salida del país - conduce a la dispersión de la mayor parte de esa intelectualidad artística por tierras de América y Europa. No obstante, en los 9o, sobre todo en su primera mitad, siguen apareciendo, si bien cada vez más esporádicamente, obras cinematográficas, narrativas, teatrales, etcétera en las que sobrevive el espíritu crítico de "los 8o".

A continuación examinaremos no las medidas administrativas, sino el discurso que las legitima y, en general, la ideología y las prácticas culturales movilizadas contra la actitud crítica del intelectual, el carácter público de su intervención, y hasta contra la propia figura del intelectual en general. Y lo haremos de una manera tipológica, sincrónica, sin atender a la propia historia interna de esa ideología y prácticas ni a las variaciones de su presencia histórica en la vida nacional, cuyo examen requeriría todo un libro. Ellas, que se presentan a sí mismas como garantes de la estabilidad ideológica y política de la Revolución, han llegado a ser hegemónicas en determinados períodos, pero, felizmente, nunca han llegado a reinar de manera absoluta en todas las instancias y ramificaciones del poder político y de las instituciones culturales. Precisamente la resistencia que a ellas le han opuesto en determinados momentos instituciones como la Casa de las Américas y el Instituto Cubano de Arte e Industria Cinematográficos, o la Unión de Escritores y Artistas de Cuba y el propio Ministerio de Cultura - ambos partícipes de ellas en otros momentos-, ha permitido la aparición o supervivencia de determinados espacios intelectuales críticos.

En el marco de esa ideología y prácticas anticríticas, el papel del intelectual revolucionario como crítico de la propia realidad social revolucionaria raras 
veces es negado abiertamente, pero también raras veces es afirmado o reafirmado sin ambages; la mayor parte del tiempo es silenciado o mencionado de paso como un mero rasgo secundario o facultativo. Pero, incluso cuando se lo reconoce explícitamente en la teoría, es neutralizado de inmediato con restricciones y reservas de diverso alcance y naturaleza, y su desempeño en la práctica social concreta deviene objeto de toda clase de acusaciones políticas y éticas.

Las más radicales restricciones son, desde luego, las planteadas en nombre de la Raison d'État: no conviene, o no se debe permitir, la crítica social en la esfera pública

a) porque los enemigos internos y externos de la Revolución podrían aprovecharla con fines propagandísticos, y/o

b) porque el conocimiento de ciertas verdades (dificultades y defectos de la realidad social) podría desorientar, confundir y desalentar al pueblo, que aún no tiene la preparación necesaria para asimilarlas [Nota bene: se trata del mismo pueblo cuya cultura política, madurez y lucidez ideológicas son presentadas como extraordinarias cuando es cuestión de destacar el carácter racional de su apoyo a la Revolución], y/o

c) porque cada nueva discrepancia crítica constituiría una heterodoxia, una disidencia que rompería la monolítica unidad ideológica de la nación, tan necesaria para su supervivencia.

Ahora bien, si se acepta que la crítica social en la esfera pública pone en peligro la seguridad nacional, al intelectual revolucionario, en la práctica, sólo le queda realmente, en el "mejor" de los casos, el silencio o el papel de apologista, cantor de lo positivo realmente existente, y, en el peor de los casos, el papel de idealizador e idilizador de la realidad social.

La Raison d'État dio origen al Síndrome del Misterio. Así bautizó el lenguaje popular cubano la tabuización de la investigación y la discusión pública de fenómenos sociales que encierran (o pudieran encerrar) algún elemento negativo endógeno. Esa tabuización, que ha existido con amplitud y rigor variables en los diversos períodos, penetró en las esferas más triviales de la vida cotidiana y llegó en ocasiones a extremos grotescos.

Muchas veces, para el intelectual, no es siquiera cuestión de hacer que el "pueblo", "el público", tome conciencia de un determinado fenómeno social 
negativo, sino simplemente de lograr que ese fenómeno, secreto a voces, sea discutido colectivamente en la esfera pública. Por ejemplo, la existencia de prostitución en Cuba fue uno de los grandes temas tabú: mientras a fines de los 8o casi todo el pueblo sabía de su abierta y creciente existencia en las calles, el discurso oficial seguía negando su existencia, y justamente del medio intelectual surgió el artículo testimonial que sacó a debate público el indeseable fenómeno. También gracias a la intervención de la intelectualidad artística, algo semejante está ocurriendo en nuestros días con otro tema tabú: la supervivencia del racismo en Cuba.

Conjuntamente o no con las antes mencionadas restricciones, al papel crítico de la intelectualidad en la esfera pública se le fijan límites relativos al dominio de acción de su competencia. Se afirma que la intelectualidad no debe ocuparse de intervenir públicamente sobre problemas sociales no estrictamente culturales o político-culturales, puesto que no es competente para ello, carece del conocimiento teórico y empírico de la realidad social concreta que es propio de los políticos profesionales y los "expertos" o "especialistas" en determinados problemas sociales.

Esta concepción, que refuerza y es reforzada a su vez por la ya señalada falta de interés de muchos de los propios intelectuales en la crítica social pública, dicta el perfil temático de las publicaciones culturales locales. Si se comparan las revistas culturales cubanas con sus homólogas de la antigua Europa del Este - por ejemplo, La Gaceta de Cuba con la soviética Literatúrnaia Gazeta-, salta a la vista el carácter estrictamente artístico-cultural de los temas abordados por las cubanas (salvo recientes excepciones), la ausencia en éstas de temáticas sociales - como la ecología, la educación, la moral, el modo de vida y, hasta hace poco, pero todavía presentes en grado mínimo, la religión, la raza y el género.

Adicionalmente, a menudo se afirma que, ya en el dominio estrictamente cultural, el intelectual debe ocuparse de intervenir críticamente sólo sobre obras literarias y artísticas particulares, y no sobre las instituciones culturales y sociales y su influencia en la producción, difusión y recepción de esas obras. En momentos en que cada vez más teóricos y críticos no marxistas de todo el mundo están reconociendo la esterilidad de una crítica "ergocéntrica" —esto es, concentrada en las obras como si éstas estuvieran suspendidas en un vacío comunicacional social- y la necesidad de investigar esas obras en el contexto de los procesos sociales de producción, difusión y recepción, en el seno del socialismo cubano se llega a esperar de la crítica marxista, entre otras, que no 
investigue los aspectos sociales de la comunicación social artística, que sea menos sociológica, es decir, que sea menos marxista o que deje de serlo.

El más frecuente modo de atacar las intervenciones críticas de la intelectualidad en la esfera pública no es, como sería de esperar, el señalamiento de las consecuencias negativas que supuestamente sus afirmaciones críticas pudieran tener, ni, mucho menos, la demostración del carácter supuestamente erróneo de esas afirmaciones, sino la atribución de condenables intenciones ocultas a sus autores: los intelectuales o parte de ellos son acusados de pretender convertir a la intelectualidad en la Conciencia Crítica de la sociedad, o sea, en la única, exclusiva conciencia crítica de ésta. ${ }^{12}$ Ello a contrapelo de algo obvio: que la intelectualidad podría aspirar a ello y lograrlo únicamente en una esfera pública en la que el resto de la sociedad no interviniera críticamente ni pudiera hacerlo; pero la intelectualidad, claro está, no tiene modo alguno de impedir tal intervención. Sólo la ausencia de actividad crítica pública por los otros sujetos sociales (clases, grupos, organizaciones políticas, medios masivos, etcétera) puede hacer que la intelectualidad no sea una conciencia crítica entre otras, sino la conciencia crítica.

Otro modo frecuente de descalificar las intervenciones críticas de la intelectualidad es estigmatizarlas públicamente con el epíteto "hipercríticas", lo cual resulta legitimación suficiente para su exclusión de la esfera pública. En correcto español, "hipercrítico" se aplica a lo que contiene una crítica excesivamente minuciosa, escrupulosa o rigurosa. Si lo condenable del hipercriticismo no es la minuciosidad, la escrupulosidad y la rigurosidad en el análisis y la valoración críticos de la realidad social, debe ser entonces el grado excesivo de esas cualidades: el que ellas se presenten "en más cantidad que lo necesario o conveniente". O sea, que el criterio de la crítica social correcta no sería la verdad, sino la correspondencia de su grado de minuciosidad, escrupulosidad y rigurosidad a cierta medida de lo necesario o conveniente. Sin embargo, ninguna intervención crítica es estigmatizada como "hipocrítica" o "acrítica". No criticar del todo o criticar menos de lo necesario o con-

12 [Adición de 2002] He hallado un solo caso en el que esa acusación habría estado justificada: en la conclusión de su ponencia "El intelectual en la revolución", presentada en el Congreso Cultural de La Habana (1968) y publicada en RC - 5 (febrero 29 de 1968), Ambrosio Fornet formuló con total explicitez lo que consideraba toda una obligación del intelectual: "Y como no es posible detenerse y cada paso es decisivo, como no hay más fórmula que una audacia y una insatisfacción permanentes, el intelectual está obligado a ser el crítico de sí mismo y la conciencia crítica de la sociedad" (p. 47). 
veniente no es motivo de condena y exclusión. Esto deja ver que el "cero", la total ausencia, es, en realidad, el grado ideal de crítica social. Ahora bien, una vez más, ¿quién, cómo y según qué criterios decide qué grado de rigurosidad crítica es necesaria o conveniente para la sociedad socialista?; o, lo que es lo mismo, ¿cuánta verdad y cuánto silenciamiento de la verdad son necesarios o convenientes? ¿Y cuánto silenciamiento de la verdad da origen a una mentira por omisión?

Un recurso de invalidación similar al anterior, y a menudo asociado a él, es la falaz exigencia gnoseologista realista-socialista del reflejo de la totalidad de la sociedad no ya por el conjunto de las obras de una cultura, sino por la obra literaria, artística o científico-social individual. Ésta ha de ser un microcosmos en el que no se puede omitir nada. Así, se condenan tajantemente las intervenciones críticas porque se concentran en revelar lo negativo y no presentan del todo o en su magnitud real (por su proporción estadística o su significación social) lo positivo que existe en la sociedad al lado de lo negativo criticado. Sin embargo, las mayoritarias intervenciones no críticas, o incluso absolutamente apologéticas, no son anatematizadas en modo alguno por concentrarse en lo positivo y no mostrar del todo o en su magnitud real lo negativo que sobrevive o surge en la sociedad al lado de lo positivo ensalzado.

Tal vez el más incapacitador de los ataques es el que se limita a señalar en la intervención crítica del intelectual alguna coincidencia con afirmaciones anteriores de contrarrevolucionarios externos o internos. Tampoco en este caso rige el principio de la correspondencia a la verdad, sino la "lógica" de lo que ya el propio Engels llamó burlonamente "política de Gribul", consistente en la supuesta obligación que tendría todo pensador marxista de afirmar automáticamente lo contrario de lo que haya afirmado cualquier autor nomarxista. Pero esta "lógica" también es aplicada retroactivamente: si algún enemigo declarado de la Revolución afirma públicamente que coincide en algo con una anterior intervención crítica del intelectual, o da alguna muestra directa o indirecta de aprobarla, ésta se convierte automáticamente en contrarrevolucionaria, independientemente del tiempo transcurrido desde su recepción inicial. Si lo políticamente correcto es lo contrario de lo que digan los enemigos, el intelectual revolucionario y su obra se ven sometidos a una azarosa y penosa dependencia intelectual respecto de la iniciativa de aquellos.

Otro modo de descalificar intervenciones críticas de intelectuales es culparlas de "indisciplina”, de introducir anarquía y desorden en la vida social. Se 
llama a desatender el contenido de verdad de una intervención crítica por el mero hecho de que ésta ha violado las reglas pragmáticas no escritas, pero no por ello menos rigurosas, que deciden dónde, cuándo, cómo y ante quién no se debe plantear una crítica sobre determinados temas (e incluso quién no debe plantearla). Basta, por ejemplo, que haya sido realizada fuera del correspondiente círculo de autorizados, fuera de las instituciones o reuniones programadas, o por una persona (principiante o aficionado) no reconocida institucionalmente como una figura intelectual, o sin rodearla de rituales apologéticos "constructivos", o sin ofrecer ya lista la solución del problema planteado, para que se pueda desautorizarla de manera absoluta y declarar innecesaria - y también improcedente- toda respuesta a ella.

Un modo particularmente eficaz y socorrido de descalificar las intervenciones críticas es su presentación, patética y casi siempre melodramática y kitsch, como una "ofensa a la sensibilidad popular", una "herida infligida a las fibras más profundas del corazón de nuestro abnegado pueblo”. Del mismo modo que en materia de comprensibilidad de las obras se busca - como bien señala una célebre frase de Che Guevara-, "lo que entiende todo el mundo, que es lo que entienden los funcionarios", en materia moral y política sólo se busca lo que aprueba todo el mundo, que, en realidad, es lo que aprueban los funcionarios. Así, de repente la "sensibilidad popular", a veces desatendida por los mismos funcionarios en otros asuntos sociales, es presentada como la suprema e infalible instancia moral y política, aunque a menudo no es más que un constructo mass-mediático u oratorio que encarna lo que los funcionarios consideran que el pueblo tiene el deber de sentir sobre tal o cual asunto.

Por último, cuando la argumentación crítica del intelectual se realiza, de manera muy visible y consecuente, desde el punto de vista de los principios e intereses de la Revolución y con una impecable lógica marxista, entonces es posible que se recurra a un mecanismo neutralizador de emergencia: en vez de discutir públicamente sus afirmaciones, de impugnarlas con las armas intelectuales del marxismo, se acusa al autor de estar simulando que es revolucionario o marxista, de disfrazarse con una fraseología marxista, con lo cual se da por zanjada la parte intelectual del asunto y se hace el correspondiente daño moral a un verdadero revolucionario o marxista.

Ahora bien, la actividad crítica del intelectual en la esfera pública no sólo es combatida directamente, sino también por vías indirectas. Una de ellas es la administración de la memoria y el olvido. En cada período se trata de borrar (minimizar, velar) de la memoria colectiva cultural todo lo relativo a la 
actividad crítica del intelectual en el período anterior: ora el recuerdo de las formas que asumió, las vías que utilizó, los espacios en que se desarrolló y las personalidades concretas que la ejercieron, ora el recuerdo de cómo se la combatió, reprimió o suprimió, y quiénes fueron sus antagonistas (lo cual, en la incierta primera mitad de los 9o, vino a facilitar el "lavado de biografías", el "travestismo ideológico" y el "reciclaje" de personajes de línea dura).

Así pues, empleando convencionalmente la nada exacta designación de los períodos con números redondos, podemos decir que las intervenciones y espacios críticos de "los 6o" (1959-1967) fueron borrados en "los 7o" (19681983); los "errores" políticoculturales cometidos contra esas intervenciones y espacios en "los 70", fueron superficialmente reconocidos e inmediatamente borrados en "los 8o" (1984-1989); y, por último, las nuevas intervenciones y espacios críticos de "los 80" fueron borrados en los 9o. Los modos de operación han ido desde la burda exclusión de diccionarios y textos históricos hasta la sutil aceptación inmediata, en "los 80", de la eufemística denominación "quinquenio gris" (1971-1975) para el período de autoritarismo y dogmatismo que, por una parte, se extendió por unos quince años, aproximadamente desde 1968 hasta 1983, y, por otra, fue negro para muchas vidas y obras intelectuales.

No es, pues, casual que las intervenciones críticas de "los 80" hayan realizado un empeño de rescatar la memoria de sus precedentes de "los 6o" como una tradición interrumpida. También el rescate de la memoria de la joven plástica y demás manifestaciones críticas de la intelectualidad de "los 80" deberá formar parte de la tan necesaria anamnesis histórica de la intelectualidad cubana, frente a aquellos que se esmeran en hacer realidad lo que proclamaba desde su título aquel viejo libro de Aldo Baroni: Cuba, país de poca memoria.

Idéntico sentido que esa administración de la memoria y el olvido tiene el hecho de que, del corpus de la producción intelectual de la Europa oriental socialista que se ha presentado al público cubano, se han excluido a priori o expulsado a posteriori las obras que encarnan una tradición intelectual socialista de crítica de la realidad social del socialismo realmente existente: desde los textos satíricos de Maiakovski hasta los de Stratíev, desde los ensayos políticos de Trotski hasta los de Adam Schaff o el primer Rudolf Bahro.

Otra vía indirecta, pero sumamente efectiva, de lucha contra la intervención crítica de la intelectualidad es el atizamiento y propagación del antiintelectualismo, ya preexistente en la cultura cubana, pero avivado y difundido con fines políticos 
En efecto, ya en 1925, en su ensayo "La crisis de la alta cultura en Cuba", el destacado pensador cubano Jorge Mañach, al enumerar los factores responsables de aquella crisis en la joven República, señalaba que en el pueblo, en “todas las clases no intelectuales de la Nación”, existía "una sorda antipatía, un irónico recelo", una "actitud de displicencia y hasta de menosprecio hacia las inquietudes intelectuales". Y observaba: "No sólo entre el pueblo bajo, sino hasta entre la burguesía, el ser o parecer 'intelectual' es una tacha”. ${ }^{13}$ En esta temprana "tradición" se manifestaba la influencia del antiintelectualismo, diverso pero profundo, de dos culturas, la española y la estadounidense, que participaron en la génesis y la evolución de la cultura cubana.

Así, en los "70" la imagen del intelectual en la cultura masiva (canciones, telenovelas, espectáculos cómicos, etcétera), se tornó más ridícula y antipática, no sólo como tipo no popular, sino, en general, como personaje carente de "cubanía” (ajeno a la realidad social, al pueblo, al trabajo duro; aristocrático, pomposamente retórico y pedante).

$\mathrm{Si}$ "las masas", "el pueblo", habían sido construidos alguna vez como el Otro de la élite intelectual —el término definitorio en la oposición-, y, por ende, primitivo, obtuso, irracional, etcétera, es la "élite" intelectual la que fue construida entonces como el Otro del "pueblo", y, por ende, extravagante, amoral, extranjerizante.

Aprovechando las ideas morales reinantes en amplios sectores populares, la homofobia (más exactamente, la gayfobia) y la hostilidad e intolerancia hacia toda diferencia en el modo de vida (y, por ende, hacia todos los signos de originalidad en el vestir, etcétera, tan frecuentes entre los intelectuales), se operó una identificación de intelectualidad, homosexualidad, "extravagancia” y no confiabilidad política y moral. Ya Pierre Bourdieu ha llamado la atención sobre "el antiintelectualismo viril" y "la tendencia de las fracciones dirigentes [de la clase dominante] a concebir la oposición entre 'el hombre de acción’ y 'el intelectual' como una variante de la oposición entre lo masculino y lo femenino". 14

El internacionalmente conocido film cubano Fresa y chocolate [1993] —al que en Cuba le ha sido vedada hasta hoy la masividad de la difusión nacional televisiva - puede ser visto también como una respuesta artística tardía de la intelligentsia nacional a la gayfobia y, en general, la "alofobia" moral e ideo-

13 Jorge Mañach: Ensayos, Letras Cubanas, La Habana, 1999, pp. 32 y 33.

14 Pierre Bourdieu: La distinction: Critique social du jugement, Éditions du Minuit, París, 1979, pp. 361-362. 
lógica realmente existentes en el seno del pueblo, pero atizadas y dirigidas en los 70 contra la intelectualidad como un todo ${ }^{15}$ (se recordará el peso de lo intelectual y la cultura en la imagen del protagonista homosexual, así como el carácter de iniciación cultural que reviste su relación de amistad creciente con el joven comunista heterosexual).

Ahora bien, portadores de ese antiintelectualismo son no sólo gran parte de los políticos y de las capas populares: también en nuestro país se ha hallado un buen número de los que Leszek Kolakowski ha llamado "intelectuales contra el intelecto". Sin embargo, la explicación que de su surgimiento ofrece Kolakowski - una sensación de "desarraigo", de no integración, y la derivada necesidad de una sensación de compromiso total o de una conciencia de pertenencia- no parece válida en este caso. ${ }^{16}$ Más apropiada parece la explicación que de ese "antiintelectualismo desde adentro" ha ofrecido Bourdieu: el resentimiento y "la violencia del amor desilusionado" que surge en intelectuales mediocres "cuando el relativo fracaso viene a condenar sus aspiraciones iniciales a propósito de una cultura de la que ellos esperaron todo". ${ }^{17}$ Así lo indica el hecho de que el auge del antiintelectualismo en el medio cultural coincide con el período que ya muchos han descrito como el de "la mediocracia", el "ascenso de la mediocridad al poder", etcétera.

Tan profundo éxito y arraigo tuvieron esas campañas antiintelectuales que todavía en 1992 el Consejo Nacional de la Unión de Escritores y Artistas de Cuba hubo de emitir un documento dedicado en gran parte a criticar los "prejuicios anticulturales" y a las personas que provocan la hostilidad y desconfianza del pueblo hacia los intelectuales. ${ }^{18}$

Ahora bien, en sus respectivos momentos de incidencia en la esfera pública la mayoría de los intelectuales críticos cubanos ha creído más que muchos políticos en la capacidad del socialismo para soportar la crítica

15 "Los medios culturales no pueden servir de marco a la proliferación de falsos intelectuales que pretenden convertir el esnobismo, la extravagancia, el homosexualismo y demás aberraciones sociales, en expresiones del arte revolucionario, alejados de las masas y del espíritu de nuestra Revolución." “Declaración del Primer Congreso Nacional de Educación y Cultura”, en: Casa de las Américas, La Habana, núm. 65-66, p. 16.

16 Leszek Kolakowski: Intelectuales contra el intelecto, Tusquets Editores, Barcelona, 1986, p. 112.

17 Pierre Bourdieu: Les règles de l'art: Genèse et structure du champ littéraire, Éditions du Seuil, París, 1992, p. 388.

18 La cultura cubana de hoy: temas para un debate, documento aprobado por el Consejo Nacional de la UNEAC el 26 de mayo de 1992, pp. 5-8. 
abierta. Más aún, la han considerado, no una amenaza para el socialismo, sino su "oxígeno", su "motor": una necesidad para la supervivencia y salud del proceso revolucionario. En su convicción, la crítica social sólo puede ser una amenaza cuando se la silencia o incluso se la desalienta con represalias administrativas o de otra índole, cuando se la confina a un enclave gremial o institucional cerrado, cuando se la coloca en un vacío comunicacional bajo una campana de vidrio, y, sobre todo, cuando no se la responde, o cuando, incluso reconocida como acertada, no es tenida en cuenta en la práctica política. Para ellos, lo que confirmaron los procesos que llevaron al derrumbe del campo socialista no fue - como piensan muchos políticos, burócratas, tecnócratas y econócratas- que la crítica social de los intelectuales determina la erosión y caída del socialismo realmente existente, sino que el silenciamiento, confinamiento y desdeñamiento de la crítica social realizada por la intelectualidad y el pueblo en general permite que los problemas sociales y los correspondientes malestares crezcan, se multipliquen y se acumulen más allá de lo que una tardía apertura del debate crítico público podría enfrentar.

La suerte del socialismo después de la caída del campo socialista está dada, más que nunca antes, por su capacidad de sustentar en la teoría y en la práctica aquella idea inicial de que la adhesión del intelectual a la Revolución - como, por lo demás, la de cualquier otro ciudadano ordinario- "si de veras quiere ser útil, no puede ser sino una adhesión crítica”; por su capacidad de tolerar y responder públicamente la crítica social que se le dirige desde otras posiciones ideológicas - las de aquellos "no revolucionarios dentro de la Revolución” a quienes se refería la célebre máxima de 1961—; por su capacidad, no ya de tolerar, sino de propiciar la crítica social que de su propia gestión se hace desde el punto de vista de los mismos principios, ideales y valores que proclama como propios, esto es, de ser el mecenas de la crítica socialista de su propia gestión; en fin, por su capacidad de asegurar que el intelectual, para publicar la verdad, no tenga que apelar al "samizdat" o al "tamizdat", 19 esferas públicas diaspóricas y otros espacios culturales y mecenazgos extraterritoriales, ni vencer las "dificultades al escribir la verdad" señaladas por Brecht

19 “Tamizdat”, neologismo ruso, construido por analogía con "samizdat" a partir de "tam" ("allá”) e "izdat” (apócope de “izdatelstvo", “editorial”). Designa las ediciones norteamericanas, euroccidentales, etcétera, de textos de autores soviéticos y de otros países del bloque socialista que, por decisiones gubernamentales, no podían ser publicados en sus respectivos países de origen. (N. del A.) 
en su célebre artículo de $1935 .{ }^{20}$ Pero mientras esta capacidad se vea dañada por la acción de las fuerzas políticas hostiles a la crítica social, el intelectual, para vencer esas dificultades, tendrá que dar muestras de las correspondientes cinco virtudes brechtianas: el valor de expresar la verdad, la perspicacia de reconocerla, el arte de hacerla manejable como un arma, el criterio para escoger a aquellos en cuyas manos ella se haga eficaz, y la astucia para difundirla ampliamente.

\section{Unhappy Happening: En torno a un rechazo en la recepción cubana del pensamiento francés sobre la literatura y las artes ${ }^{21}$}

Se trata de un caso de recepción de una teoría estética francesa en el que predomina el rechazo y, finalmente, se impone la exclusión de la vida cultural e incluso de la memoria cultural. Me refiero al destino del pensamiento francés sobre el happening en Cuba y, en particular, a la negativa a publicar textos de Jean-Jacques Lebel y Alain Jouffroy sobre dicha nueva teoría y práctica artísticas. El paralelo destino, no menos trunco, de las tentativas de realizar en Cuba happenings o espectáculos con elementos de happening, emprendidas por algunos teatristas, es un tema que espera por un historiador con la inquisitividad de un Rine Leal, sobre todo cuando son ignoradas hasta por jóvenes estudiosos de los años 90 (como es el caso de Glenda León en su cuaderno $L a$ condición performática, cuando, luego de afirmar -inargumentadamente y en contradicción con sus teóricos y prácticos- que happening y performance son un mismo fenómeno, comienza la historia de éste en Cuba a partir de ciertas realizaciones del artista plástico Leandro Soto en los 80). ${ }^{22}$

Como, probablemente, algunos de ustedes saben, en los últimos años he venido dando a conocer en Cuba algunos textos de autores extranjeros que,

20 Bertolt Brecht: "Fünf Schwierigkeiten beim Schreiben der Wahrheit" (1935), Schriften zur Literatur und Kunst, Aufbau-Verlag, Berlín y Weimar, 1966, tomo I, pp. 265-290.

${ }_{21}$ Ponencia leída en el Encuentro Cuba-Francia sobre la recepción del pensamiento teórico francés en Cuba, celebrado en el marco de la XI Feria Internacional del Libro, febrero del 2002. Publicada en La Gaceta de Cuba, La Habana, núm. 5, 2002, pp. 21-25. La presente versión fue publicada en: Desiderio Navarro (2006), Las causas de las cosas. La Habana, Editorial Letras Cubanas: 32-42.

22 Nota del 2002: Baste señalar que el texto "Sobre la puesta en escena" en el programa de La noche de los asesinos por Vicente Revuelta y Teatro Estudio, montaje paradigmático de la vanguardia artística cubana de los 6o, concluye precisamente con las palabras: "El 'happening' nos ha sido útil." 
por motivos ideológicos o político-culturales, en los años 70, o incluso ya a fines de los años 6o, fueron arrancados de las pruebas de plana o ni siquiera pudieron llegar al linotipo: en 1994 Casa de las Américas dio a conocer las brillantes y esclarecedoras respuestas de Cortázar desde París, en 1971, a un cuestionario mío sobre su poética; también en 1994, La Gaceta de Cuba publicó una entrevista que sostuve con Marguerite Duras en 1967; y en el prólogo a mi antología Intertextualité (1997) he contado cómo "ya estaba en imprenta, en galeras que aún conservo, 'La expansión de la semiótica’, de Julia Kristeva, cuando la radicalización, recién oficializada en el Primer Congreso de Educación y Cultura (1971), del viraje político-cultural iniciado en 1968, determinó su exclusión de las páginas de La Gaceta de Cuba". Y entre los textos de corte teórico - ora de mi autoría, ora de autores extranjeros- entonces rechazados por varias publicaciones periódicas y una editorial cubana, cuyas galeras o manuscritos aún conservo inéditos, figuran una entrevista sobre el happening que, durante la muestra del Salón de Mayo en Cuba en 1967, sostuve con Alain Jouffroy, uno de los ensayistas y críticos franceses más prominentes del momento, y mi traducción de una recopilación de textos sobre el happening de Jean-Jacques Lebel, uno de los principales teóricos y prácticos de dicho fenómeno a nivel mundial. Los textos allí reunidos eran tres: los de su libro El happening (Denoël, 1966) y su cuaderno Carta abierta al mirante (1966), así como un prólogo que el propio Lebel escribió especialmente para mi edición cubana. En el mismo año 1967, sólo unos meses después de la negativa del Instituto Cubano del Libro a publicar mi recopilación, en Argentina, país siempre tan atento a los últimos acontecimientos del pensamiento mundial, las Ediciones Nueva Visión publicaron un volumen que incluía los textos del libro y del cuaderno de Lebel.

Ahora bien, ¿qué sentido y provecho puede tener el ocuparnos de una recepción que, por dicho rechazo, no dio lugar a ninguna apropiación local de importancia, y de la teoría de un fenómeno como el happening, que ya forma parte, por así decir, del museo de la neovanguardia artística de la segunda mitad del siglo xx? ¿Para qué hacerlo?

Respondo de la manera más concisa posible: para conocer mejor la cultura cubana de los últimos cuarenta años. Como es bien sabido luego del descrédito generalizado de la "influenciología", las recepciones no tienen nada de pasivo y nos dicen más sobre la cultura que activamente se apropia o rechaza un fenómeno teórico o artístico foráneo, que muchos fenómenos totalmente "endógenos" de esa cultura. Para la comparatística actual, es tan importante 
saber si en tal o cual cultura se produjo una recepción, digamos, del romanticismo o el naturalismo foráneos, como saber si no se produjo, si hubo indiferencia o rechazo y por qué.

La disolución del sujeto creador individual en buena parte de la teoría y la práctica artísticas europeas y norteamericanas de los años 6o-8o, ha sido considerada por muchos y muy diversos investigadores y críticos uno de los fenómenos que mejor señalan y caracterizan el paso de un período moderno a un período postmoderno en la cultura occidental. Considero que también en el pensamiento cultural y la producción artística cubanos de fines de los 60 a principios de los 80 se produjo un asalto al sujeto creador individual de la estética y el arte modernos, y que también en ese pensamiento y producción la Auflösung del sujeto humanista indica un profundo cambio periodizacional. Sin embargo, mientras que el postmodernismo, sobre todo con sus teorías sobre "la muerte del autor" o sobre "la desaparición del yo" (Selflessness, depthlessness), apuntó al autor individual como Dios Padre, origen y dueño del significado único de la obra, o como subjetividad profunda que se exterioriza en la obra, en la cultura cubana de esos tres lustros (68-83) el blanco de los cuestionamientos fue el sujeto individual dotado y competente como creador de la obra artística, o sea, la estética moderna del genio, del don natural, del carisma, de la subjetividad única e insustituible.

La concepción estética y la práctica artística modernas del sujeto individual dotado y competente como creador de la obra artística fueron cuestionadas e impugnadas radicalmente por el discurso político-cultural, la teoría y la práctica artísticas sobre todo a partir del Primer Congreso de Educación y Cultura (1971). Múltiples fenómenos culturales que cristalizan entre 1970 y 1975 aproximadamente, a primera vista muy heterogéneos y hasta hoy día no tratados conjuntamente, al ser analizados y comparados desde el punto de vista de su relación con ese cuestionamiento e impugnación, dejan ver una lógica global que hace del período examinado el más coherente - tristemente coherente, es cierto - de la cultura cubana posterior al triunfo revolucionario de 1959. Me refiero a fenómenos tan diversos como la exaltación teórica y la aparición o el auge, en la práctica creadora, del género testimonial, el Teatro Nuevo, el fotorrealismo, el papier maché, el arte naïf o primitivo, el folclorismo, el arte de aficionados, la teoría del talento poético universal, etcétera. Todos esos fenómenos particulares constituyen - desde luego, entre otras cosas- diversas manifestaciones de una misma tendencia, anti-moderna pero no-postmoderna, a la disolución del sujeto individual dotado y competente 
como creador de la obra artística. Subrayo de entrada enérgicamente que no creo, en modo alguno, que esa tendencia explique, en su totalidad o en su mayor parte, la génesis de esos fenómenos, sino que estamos ante casos de sobredeterminación en los que, junto a ella, actúan otras razones históricas más o menos poderosas -en primer término, la lógica interna de desarrollo de los respectivos campos artísticos (por ejemplo, la "novela antropológica" de Lewis y Pozas en el caso del testimonio, el Teatro de Creación Colectiva latinoamericano en el caso del Teatro Nuevo, el fotorrealismo de la neovanguardia estadounidense y europea en el caso del fotorrealismo local). Y, desde luego, tampoco creemos que la génesis de tal o cual género u orientación artística decida sobre los valores artísticos de sus realizaciones concretas.

De una manera análoga a como Freud hallaba en las diferentes formas que puede tomar la paranoia (delirios de persecución, de celos, de grandeza, etcétera) formas diversas de contradecir una proposición única: "Yo lo amo" ("Yo no lo amo, él me odia", "Yo no lo amo, ella lo ama”...), nosotros creemos que pueden verse en los fenómenos culturales antes enumerados diversas formas de contradecir una sola proposición: "La obra de arte es una creación de un sujeto individual excepcionalmente dotado y competente." Ora se niega el carácter de creación de la actividad del sujeto, ora el carácter individual de éste, ora la necesidad o la existencia de un don o talento artístico natural, ora el carácter demográficamente excepcional, infrecuente, de ese don, ora la necesidad de una especial competencia artística, ora varios de esos aspectos a la vez. Esta negación asume formas diversas y más o menos radicales en las diversas esferas culturales en que se presenta.

Por ejemplo, el autor del testimonio es presentado como un mediador, registrador, mero escribano y editor del discurso de un otro no-intelectual, y el autor del fotorrealismo, como un reproductor impersonal de una imagen fotográfica. En la teoría del talento poético universal (Mirta Aguirre), así como en el culto del papier maché y del folclor, se niega el carácter demográficamente excepcional o infrecuente del "don" poético o artístico y se afirma la presencia de éste en todos y cada uno de los seres humanos. En la exaltación del arte de los naïfs o primitivos se niega la necesidad de una especial competencia o instrucción artística y se afirma la universalidad del "don" artístico, mientras que en la exaltación del arte de aficionados, a la inversa, se niega la existencia de tal don y se considera que la transmisión de conocimientos mediante la educación artística es condición suficiente para convertir a una persona en artista. 
Del artista como creador, generador individual de ideología en virtud de un don o una competencia supuestamente monopolizada, y representado como "el brujo" de la tribu, se debía pasar al artista como reproductor, transmisor, ilustrador, preferiblemente colectivo, de ideología generada por otro fuera del arte, y el nuevo paradigma del intelectual revolucionario - y hasta el anunciado sustituto del artista moderno en calidad de artista él mismo, gracias a la instrucción artística masiva de los profesionales de la enseñanza, anunciada en el I Congreso de Educación y Cultura - sería el maestro de escuela, como mero transmisor de contenidos cognoscitivos e ideológicos generados por otro, en otra instancia, extraartística. El objetivo social de esa negación era determinar un cambio del status y rol del artista en la comunicación social e impedir que éste fuera una fuente de heteroglosia en el espacio ideológico, como ya venía ocurriendo desde 1968 aproximadamente.

En el campo de las artes escénicas, la ideología estética del Grupo Escambray y otras formas del Teatro Nuevo también participaba en el asalto al sujeto creador individual moderno, a la ideología del teatro centrada en el dramaturgo, el director o el actor individuales, como eran las del Teatro de la Crueldad, el Teatro del Absurdo, el Teatro Pánico y el Teatro Laboratorio de Grotowski, tan influyentes y discutidos por entonces en los medios teatrales. Y lo hacía al propugnar un sujeto creador colectivo que incluiría al público antes, durante y después de la representación.

Ahora bien, también el happening se declaraba "arte de participación", propugnaba "el principio de integración escena/auditorio" y reclamaba "la intervención (y no ya únicamente la contemplación) del espectador”. O, como lo formulaba Jean-Jacques Lebel en el libro rechazado en nuestro país:

El happening establece una relación de sujeto a sujeto. Ya no se es (exclusivamente) mirante, sino también mirado, examinado, escrutado. Ya no hay monólogo, sino diálogo, intercambio y circulación de las imágenes.

El happening pone en acción (en lugar de simplemente representar) las relaciones variadas entre los individuos y su ambiente psicosocial.

$\mathrm{O}$, como afirma un manifiesto de organizadores de happenings, entre cuyos firmantes hallamos también al mundialmente célebre e influyente Joseph Beuys (influyente también en la plástica cubana de los 80): 
Toda persona presente en un happening participa en él. Es el fin de la noción de actores, de público, de exhibicionistas, de mirantes, de actividad y de pasividad. En un happening se puede cambiar de "estado" a voluntad.

Por otra parte, como ya puede inferirse, el happening no exige ningún don o talento especial, ni competencia o instrucción artística alguna.

¿Cómo se explicaría, pues, en el marco de la interpretación aquí expuesta, que el happening, a diferencia del Teatro Escambray, haya sido rechazado tan tajantemente y no, al igual que éste, lanzado como paradigma de creación teatral?

En realidad, el happening impugnaba la ideología del sujeto creador individual, pero no propugnaba en lugar de éste, como el Grupo Escambray, la teleología de un sujeto autoral colectivo único, resultante de negociaciones entre investigadores e investigados, escritores e informantes, en las que, sin intercambio de roles posible, los primeros son los profesionales del grupo y los segundos el público local. El happening proponía el desalojo del Dramaturgo, Director o Actor como sujeto creador individual, pero con el fin de que, en su lugar, aparecieran múltiples sujetos creadores individuales —organizadores y asistentes - e interactuaran espontáneamente, dialogaran libremente. De ahí que, para la ideología local orientada a la disolución del sujeto creador individual, el happening no venía a resolver el problema, sino a multiplicarlo. Sobre todo, porque ese diálogo de sujetos, según Lebel y demás teóricos del happening, debía ser dejado a la improvisación y al azar, debía “'bajar a la calle', salir del zoológico cultural, para enriquecerse, con lo que Hegel llamaba, no sin humor, la 'impureza de lo accidental". De ahí que Lebel pudiera decir: "jamás sabemos dónde ni cómo termina un happening". $\mathrm{Si}$, además, tenemos en cuenta que los happenistas estimulaban a los participantes de los happenings a explicitar y transgredir los tabúes sexuales, y los happenistas franceses, a diferencia de los estadounidenses (Allan Kaprow et al.), también los tabúes políticos, podemos entender perfectamente que la nueva teoría y práctica artísticas hayan sido rechazadas de plano $-\mathrm{y}$ más enérgicamente que las otras novedades teatrales - por la ideología del Gran Monólogo, que, paradójicamente anticarismática en la esfera del arte y carismática en la esfera política, sitúa en esta última el Primer Motor de la cadena de meros transmisores artísticos.

Sin embargo, en contra de lo que pudiera esperarse, el principal tema de aquella breve entrevista inédita con Jouffroy no era otro que las limitaciones, 
contradicciones, fracasos y posibilidades de esa estética utopista anarquista, estética que, como las no menos politizantes y antiburguesas de Mikel Dufrenne y Hervé Fischer, ha permanecido hasta ahora desconocida por la casi totalidad de nuestros artistas e intelectuales. Para concluir, permítaseme traer de 34 años atrás las palabras finales de Jouffroy en aquella entrevista y dejar que se escuchen por vez primera:

Mas, para los que se interesan en esta cuestión y que pueden preguntarse legítimamente: “'Pero en nombre de qué decide él cuál es el buen happening, cuál el malo, y cuál el muy malo?", voy a tratar de responder. Para el espectador que, como todos los espectadores, viene simplemente al espectáculo para sentir emociones, no hay duda de que todos los happenings son muy malos, porque es muy raro sentir emociones en el momento en que se desarrolla un espectáculo en el cual uno es considerado, a pesar de uno mismo, como un actor. Cada uno estima, en efecto, que el espectáculo es una zona de la vida donde son los otros quienes actúan y no él mismo. Para echar abajo una situación tan antigua, tan habitual, es evidentemente necesario encontrar el medio más eficaz de hacerlo, y lo que siento es que los pintores y escritores que organizan happenings lo han convertido, a pesar de todo, en un nuevo género en sí mismo, no piensan nada más que en hacer un bello happening, en el que se puede reconocer de una manera demasiado flagrante las obsesiones y los problemas de un solo individuo. Para trascender el problema individual de los organizadores del happening, les convendría primeramente descubrir la ligazón del problema individual con las obsesiones colectivas. Esta ligazón existe siempre, y no sería materialista pretender que el problema de un solo individuo puede desunirse completamente del problema de la colectividad entera.

Hay aquí un fenómeno de vasos comunicantes permanentes. Es, pues, en el momento en que, asistiendo a un happening, me siento confrontado con los problemas de un hombre que no ha comprendido esa ligazón, en el momento en el que yo mismo me siento arrojado, arrastrado a un gentío que no comprende ni lo que hace, ni a lo que asiste, es en ese momento quizás que el happening me parece un fracaso, pero en ese fracaso mismo siento muy violentamente la necesidad absoluta que existe para cada uno de comprenderse hasta el fondo sin ningún velo y de obrar en el seno de este conocimiento. Si el happening favorece la aparición de una conciencia así, importa poco a fin de cuentas que sea bueno, malo o muy malo, ya que es precisamente de esa conciencia de lo que depende el futuro de la revolución. ${ }^{23}$

23 El texto completo de la entrevista a Jouffroy fue publicado en el mismo número de La Gaceta de Cuba en que apareció originalmente el presente trabajo. (N. del A.) 
De haber sido publicadas a fines de los 6o, estas palabras, además de haber influido tal vez en el destino cubano del happening - propiciando una apropiación crítica o una respuesta artística dialógica-, quizás hubieran ayudado a algunos a comprender, a fines de los 8o, por qué —en calidad de políticos o de creadores - no debían proceder con el performance como procedieron otros con el happening veinte años antes.

\section{El paisaje: problemas teóricos del género ${ }^{24}$}

La situación de la categoría de "género" en la estética es bastante singular. Aunque quedaron muy atrás los tiempos en que la estética idealista neorromántica de Croce hallaba simpatizantes para su rechazo radical del concepto de "género", todavía en 1971 el célebre estético soviético Moiséi Samóilovich Kagan se veía obligado a señalar que, hasta ese momento, dicho concepto no había llegado a ser una categoría de la ciencia estética. ${ }^{25}$ Resulta elocuente el hecho de que aún en 1972 un diccionario de estética general tan serio y actualizado como es el concebido por Marcel Breazu, Ion Pascadi y muchos otros relevantes estéticos rumanos, no incluyera entre sus definiciones la del término "género", a pesar de que en sus páginas éste fue empleado repetidamente en los artículos correspondientes a otros términos ("artes plásticas", "gráfica”, “clasicismo", "grabado", etc.). ${ }^{26}$ En los años 70, distintos estéticos prestaron cierta atención a la tarea de fundamentar la categoría de "género del arte". Para dar una idea de la divergencia existente entre las propuestas conceptuales por ellos realizadas, apuntaremos el hecho de que, si para Kagan el paisaje pictórico viene a ser — como para la teoría tradicional de las artes plásticas - un género de la especie "pintura", para la destacada estética polaca Maria Golaszewska el mismo no puede ser más que una variedad genérica del género "pintura representativa". ${ }^{27}$

24 Ponencia leída el 21 de septiembre de 1982 en el Encuentro Teórico sobre el Paisaje, organizado por la Dirección de Artes Plásticas del Ministerio de Cultura. Publicada en Unión, núm. 1, enero-marzo de 1983, pp. 101-119. La presente versión fue publicada en: Desiderio Navarro (2007), A pe(n)sar de todo. Para leer en contexto. La Habana, Editorial Letras Cubanas: 189-216.

25 Moiséi Samóilovich Kagan: Lektsii po marksistsko-leninskoi estetike, Izd-vo LU, Leningrado, 1971, p. 357.

26 Cf. Dictionar de estetica general, Editura Politica, Bucarest, 1972.

27 M. S. Kagan, ob. cit., pp. 408-409; María Golaszewska: Zarys estetyki, Wydawnictwo Literackie, Cracovia, 1973. 
Entretanto, las teorías de ciertas artes particulares han venido resolviendo el problema morfológico del género por caminos independientes y muy diversos. En efecto, la teoría de la literatura, la teoría de la música y la teoría de las artes plásticas han elaborado sus propias categorías específicas de "género", pero sólo las dos primeras han desarrollado un considerable volumen de teorización sobre éstas. Y ya esto nos conduce ante el problema que será el eje del presente trabajo: la falta de desarrollo de la teoría general de los géneros de las artes plásticas y el lamentable reflejo de esa insuficiencia en el conocimiento teórico del paisaje como género.

Permítasenos una comparación ilustrativa. En el dominio de la ciencia literaria se ha constituido, como parte de la poética, una disciplina aparte, la genología, que se ocupa del estudio de los géneros literarios. Ella, además de emprender la descripción de la estructura y el desarrollo histórico de los distintos géneros, se plantea problemas teóricos más generales, como son el modo de existencia del género, los principios que rigen sus transformaciones, el modo y el alcance de su influencia sobre la práctica creadora y sobre la recepción de las obras, la tipología de los géneros, etc. Si el estudio de las artes plásticas cuenta ya con trabajos - relativamente escasos y de muy desigual calidad- que describen el desarrollo histórico y, más raras veces, la estructura de ciertos géneros plásticos, no ha producido aún obras que aborden a fondo y con amplitud esos problemas teóricos más generales que la ciencia literaria ha sabido plantearse y a los que desde hace mucho viene dando respuestas cada vez más precisas.

Lo cierto es que sin la solución de esos problemas teóricos de máxima generalidad no podrán ser resueltas de manera plenamente satisfactoria las tareas particulares de la descripción estructural e histórica del paisaje y de los restantes géneros plásticos, porque las categorías, principios y demás generalizaciones resultantes de esa teorización en el más alto nivel son justamente los que deben servir de aparato conceptual básico y guía metodológica a esa labor descriptiva. A su vez, la plena constitución de esa "poética" teórica e histórica del paisaje y demás géneros plásticos resulta indispensable para lograr la deseada integralidad científica en el análisis de las obras plásticas individuales o de los conjuntos formados por las obras de autores, corrientes o períodos aislados. De esto se ha dado cuenta el teórico soviético I. Sapego al desarrollar su ambicioso esquema metodológico del análisis de las obras artísticas plásticas: en el segundo de los tres planos que, según él, debe encerrar el análisis, el investigador ha de discernir el círculo individual de los 
principales rasgos tipológicos que posee la obra global del autor dado, y uno de los cuatro grupos de nexos que forman ese círculo en el modelo de Sapego es precisamente "la tipología genérica de la obra global en su relación con los principios genéricos generales del arte de la época del artista, y también con las condiciones de madurez, carácter tradicional y carácter innovador de la forma genérica". ${ }^{28}$

Antes de adentrarnos en la problemática genológica escogida, se impone realizar aquí algunas precisiones y delimitaciones preliminares. Como es sabido, las artes plásticas son una "familia de artes" que — según las concepciones actualmente dominantes - incluye la pintura, la gráfica, la escultura, la fotografía artística, la arquitectura y ciertas especies de las artes aplicadas. En esa bastante bien llevada "familia", el paisaje —al igual que otros géneros de la plástica (por ejemplo, la naturaleza muerta y el retrato) - tiene el peculiar status de género múltiple: él existe como género en la pintura, en la gráfica y, por último, en la fotografía artística. Aunque se pueden señalar casos aislados de "paisaje esculpido" - por ejemplo, ciertas obras del arte hindú antiguo-, no tenemos noticias de que tales "paisajes esculpidos" hayan llegado a constituir alguna vez un género escultórico independiente en cultura alguna. Así, puesto que el paisaje ha existido como género de tres artes diversas, estamos, en realidad, no ante un solo género, sino ante tres géneros distintos: el paisaje pictórico, el paisaje gráfico y el paisaje fotográfico-artístico. Cada uno de ellos tiene su propia estructura artística (condicionada por las técnicas de representación de las respectivas artes) y su propia evolución histórica (condicionada por la evolución general de las artes de que forman parte respectivamente). Por ende, cada uno de ellos tiene derecho a su propia teoría y a su propia historia. Sin embargo, no es posible dejar de ver que existen obvios aspectos comunes a todos ellos (y también íntimos vínculos contactuales históricos, propiciados por esa comunidad de aspectos). Justamente la aprehensión empírica de esas evidentes características compartidas determinó que se los designara con el mismo nombre de "paisaje". Por consiguiente, su común carácter de "representación artística plástica de un fragmento de escenario natural" nos autoriza a tratarlos como variedades de una determinada forma supra-genérica —el "paisaje plástico"-, perteneciente a un tipo aún no bautizado por la morfología del arte.

28 I. Sapego: “K voprosam analiza proizvedeniia izobrazitel'nogo iskusstva”, en Iskusstvo, Moscú, núm. 10, 1972, p. 40. 
Sobre la base de lo expuesto, podemos precisar que nuestras ulteriores reflexiones no se ocuparán del "paisaje plástico" en general, ni del paisaje gráfico o el fotográfico-artístico en particular, sino exclusivamente del paisaje pictórico. Semejante restricción del campo al que apuntarán nuestros siguientes planteamientos no significa, en modo alguno, que no admitamos la validez de muchos de ellos —evidente en más de un caso— para el paisaje gráfico o el fotográfico-artístico.

Si descartamos la idea neorromántica de que los géneros pictóricos no existen para la práctica creadora ni para la actividad receptora, y también la tesis nominalista de que el "paisaje" y los demás géneros no son más que puros nombres, la pregunta “iexisten los géneros pictóricos?” viene a ser desplazada por una no menos general: “¿cómo existen los géneros pictóricos?"

Nuestra respuesta es la siguiente: el género pictórico tiene un triple modo de existencia: 1) como hecho de la conciencia pictórica; 2) como conjunto de propiedades reales de obras pictóricas individuales; y 3) como categoría descriptiva empleada por el teórico y el historiador de la pintura.

Para llegar a esta respuesta y para su ulterior desarrollo, hemos aprovechado en función heurística algunas tesis teoricoliterarias de Michal Glówinski y otros autores polacos. ${ }^{29}$

El género como hecho de la conciencia pictórica es el conocimiento que tienen pintores y espectadores de que existen diversas formas de obra pictórica y de que cada una de esas formas se caracteriza por ciertas particularidades que la distinguen de las demás. En este aspecto, el género se presenta como un conjunto intersubjetivamente existente de indicaciones y reglas que determinan la construcción de las obras particulares, que deciden que "así se pinta” tal o cual tipo de cuadros. Se podría decir que los géneros pictóricos son una peculiar "gramática de la pintura". El conocimiento de esa "gramática" puede expresarse en dos formas: puede estar formulado conceptualmente como un conjunto de órdenes y prohibiciones, en tratados, ensayos, o en el marco de obras críticas o históricas, etc.; y también puede permanecer latente, no formulado, como un conjunto de costumbres, un código no escrito de "buena conducta", intersubjetivamente establecido sobre la base empírica de la práctica pictórica de la época y de la tradición viva en ésta.

29 Cf. M. Glówinski: “Gatunek literacki i problemy poetyki historycznej”, en Problemy teorii literatury—2, Ossolineum, Wroclaw-Varsovia-Cracovia-Gdansk, 1976; M. Glówinski, A. Okopien-Slawinska y J. Slawinski: Zarys teorii literatury, Wydawnictwa Szkolne i Pedagogiczne, Varsovia, 1975 (cap. VI, "Podzial na rodzaje i gatunki literackie"). 
El caso de la no formulación de las reglas de un género pictórico puede ser ejemplificado con la situación del paisaje en sus inicios holandeses como género independiente durante los siglos XVI y XVII. Un ejemplo del caso contrario es la situación del paisaje en China desde el siglo IV hasta entrado el presente siglo: las reglas de la paisajística china tradicional han sido formuladas detalladamente en tratados y ensayos como "Sobre la pintura de la montaña con terrazas nubosas", de Ku K'ai-Chih, y "Prefacio a la pintura de paisaje”, de Tsung Ping. No se trata de que en un caso el género tenga carácter normativo y en el otro no. Los géneros pictóricos - como las gramáticas de las distintas lenguas - siempre son normativos, siempre son conjuntos de directivas. Aquí la diferencia reside en el tipo y grado del normativismo que se pone de manifiesto en esos casos.

El grado de normatividad de los géneros pictóricos puede ser muy diverso. $A$ veces el género es tratado como un conjunto rigurosamente obligatorio de normas, y entonces se absolutiza la forma del género que domina en la época dada y se consideran falsas, malas, las demás realizaciones presentes del género. En otras ocasiones el género pictórico es tratado pluralistamente y se admiten realizaciones diversas del mismo. El primer caso se presenta, por ejemplo, en la situación del paisaje en el período de hegemonía del clasicismo francés, mientras que el segundo puede ser ilustrado con la situación del paisaje en los últimos años del siglo xIX y los primeros años de nuestro siglo, cuando se reconocen como genuinos paisajes variadas obras de Monet y Redon, de Cézanne y el Aduanero Rousseau, de Seurat y Van Gogh, es decir, de un impresionista y un simbolista, de un precursor del cubismo y un primitivista, de un puntillista cientifizante y un pionero del expresionismo.

Sobre la normatividad del género pictórico influye el hecho de que la concepción del género existente en la conciencia pictórica de la época dada sea "presentista" o, por el contrario, "historista". La conciencia pictórica puede reconocerle valor al género sólo en la forma en que se presenta en la actualidad, o también puede tratarlo como una única tradición aceptada que en las distintas épocas ha asumido distintas formas. A decir verdad, en la historia de la pintura esos casos extremos casi nunca se dan: raras veces se niega en bloque toda la tradición de un género y nunca se aceptan todas las formas que asumió históricamente la tradición de un género. Para dar una muestra del aspecto que puede tomar la absolutización presentista, citaremos algunos fragmentos del libro que, a mediados del pasado siglo, dedicó al paisaje un célebre e influyente crítico de arte, el inglés John Ruskin. 
Las escuelas ya muertas del paisaje [...] pueden dividirse de una manera general en septentrionales y meridionales: las escuelas holandesas, más o menos naturales, pero vulgares; las escuelas italianas, más o menos refinadas, pero absurdas. ${ }^{30}$

Y refiriéndose a la escuela inglesa encabezada por Turner, escribe Ruskin: "Esta escuela moderna llega a ser la única verdadera del paisaje de cuantas existieron siempre." En consonancia, Turner es, para él, "el primer grande paisajista". ${ }^{11}$

La conciencia del género no existe al margen de la práctica pictórica concreta: por una parte, hace generalizaciones de esa práctica; por otra, influye en alguna medida sobre el curso de su desarrollo. Así pues, ello es un reflejo más o menos fiel de propiedades que existen realmente en obras pictóricas individuales y que permiten agrupar esas obras en ciertos conjuntos. En este aspecto, los géneros son tipos de estructuras presentes en las obras pictóricas, modos de construcción de esas obras, conjuntos de convenciones (esquemas, especies de temáticas, recursos) realizadas en la práctica pictórica.

Por último, el género como instrumento de descripción empleado por teóricos e historiadores de la pintura se halla en estrecha relación con el género como elemento de la conciencia pictórica y como conjunto de rasgos reales de ciertos grupos de obras pictóricas. Las manifestaciones de estos dos últimos modos de existencia le sirven de fundamento al investigador para construir el género como categoría descriptiva. Pero no son pocas ni pequeñas las divergencias que pueden surgir en la manera de abordar esa elaboración conceptual.

Unos autores pueden buscar, por la vía de una inducción lo más amplia posible, los rasgos comunes a todas las obras designadas por sus autores con el nombre de "paisaje", por ejemplo. Otros autores pueden negar la validez de las clasificaciones existentes (afirmando, por ejemplo, que no todos los llamados "paisajes" lo son realmente y que al paisaje pertenecen obras que han recibido otra denominación genérica o que no han recibido ninguna); éstos buscarán los rasgos esenciales del género en una sola obra, o en las obras más perfectas en el orden artístico, o en un círculo más amplio de obras, escogidas según otros criterios. Si la vía inductiva simple conduce a conceptos-clases cognoscitivamente pobres, la segunda conduce a conceptos tipológicos o a

30 John Ruskin: Los pintores modernos. El paisaje, trad. de Carmen de Burgos, Prometeo, Valencia, [s. f.], p. 158.

31 Ibíd., pp. 134-154. (El subrayado es nuestro —D. N.) 
tipos ideales que resultan criptonormativos. Parafraseando a un genólogo literario (G. Müller), se diría que el dilema de cada historia del género paisajístico consiste en que no podemos decir qué obras pertenecen a él sin saber cuál es la esencia del género, pero, al mismo tiempo, tampoco podemos saber qué constituye esa esencia sin saber si tal o cual obra pertenece a ese género. Y esa esencia puede ser entendida de manera extrahistórica, idealista: ora como la idea general, el eidos del paisaje, ora como la especificidad del paisaje "en general" (y en este último caso se llegaría a hablar de la "paisajidad", tal como desde hace muchas décadas se viene hablando de la "literaturidad", la "epicidad", etcétera).

Los marxistas, si bien podríamos aprovechar críticamente algunos resultados de la aplicación del análisis eidético fenomenológico a las artes plásticas - por ejemplo, los trabajos de Ingarden sobre la construcción del cuadro y la pintura abstracta-, no podemos darnos a la tarea de elaborar una fenomenología del paisaje, porque nuestros principios filosóficos son incompatibles con el intuicionismo de su modo apriorístico inmediato de conocimiento, con la idea de una esencia extrahistórica, eterna, de los productos culturales, y con el normativismo que encierra su elección de un caso individual (normativismo que puede resultar un eurocentrismo colonizante o un pasatismo negador de toda obra que, con sus innovaciones y originalidad, viniera a alterar la "esencia" del género).

El conocido investigador Max Friedländer enumeró una vez los siguientes géneros o "tipos" pictóricos: 1) retablos y demás pintura religiosa; 2) mitos, leyendas, tradiciones poéticas, escenas históricas; 3) pintura de género; 4) paisaje; 5) arquitecturas (vistas de ciudades, interiores de edificios); 6) naturaleza muerta; 7) retrato (de una sola figura, de grupo...)..$^{2}$

Esta división en géneros es aceptada, con ligeras modificaciones, por casi todos los estudiosos de la pintura. Obviamente, el criterio de la división es el principio temático. En cambio, la división de los géneros pictóricos en variedades genéricas se ha efectuado, por lo regular (una excepción son las marinas), según criterios que atienden al aspecto valorativo de la estructura artística (paisaje heroico, paisaje idílico) o al aspecto modelante de la misma (paisaje topográfico o d'après nature, paisaje alegórico). Ateniéndose a este

32 Max J. Friedländer: El arte y sus secretos (título original: Sobre arte y competencia en materia de arte), trad. de J. Bofill y Ferro, Edit. Juventud, Barcelona, 1949, pp. $74-75$. 
último tipo de criterios, Kenneth Clark ha hablado de paisaje de hechos, paisaje ideal, paisaje de fantasía y paisaje de símbolos. 33 No ocurre así en todas las artes. En la literatura, por ejemplo, sucede lo contrario: el tema no actúa como criterio en la división en géneros, pero sí interviene en la división de los géneros en variedades genéricas (novela histórica, de costumbres, social, etcétera); en cambio, son los factores composicionales, estilísticos, axiológicos y otros de índole no temática los que deciden en la división en géneros (soneto, cuento, novela, etcétera).

Un examen cuidadoso del mencionado repertorio de géneros pictóricos revela que la delimitación de ciertos géneros es muy imprecisa. Veamos, por ejemplo, lo que sobre la pintura de género como categoría se ve obligado a decirnos el propio Friedländer en otro libro, en su clásico Paisaje. Retrato. Naturaleza muerta.

Pintura de género [Genre] es un término vago con límites inciertos, más fácil de definir negativamente que positivamente. Todo lo que no sea de significación histórica, religiosa o mitológica en un cuadro que trate del hombre y sus actividades, todo lo que no esté caracterizado, exaltado o consagrado por el conocimiento, el pensamiento o la fe, cae en la categoría de pintura de género. 34

Pero la situación no es mucho mejor en lo que respecta al paisaje y al género arquitectónico (no sin motivo existe una diferencia de siglos entre las fechas a partir de las cuales comienzan su exposición los historiadores del paisaje occidental). Los problemas que plantea la clasificación de los cuadros que representan ciudades, son grandes, pues no todos los autores los incluyen, como Friedländer, en el género arquitectónico: hay quienes los insertan en el género paisajístico e incluso quienes llegan a hablar del "paisaje de ciudad” como un género independiente del arquitectónico y del paisajístico. Por ejemplo, H. Jantzen, el autor del primer libro sobre la pintura neerlandesa de arquitectura, incluyó en el género arquitectónico sólo los cuadros con representaciones de interiores. 35 Este debate en torno al status genérico de las vistas de ciudades nos recuerda las antaño frecuentes discusiones literarias respecto a si tal o cual obra narrativa era una novela corta o un cuento largo

33 Cf. Kenneth Clark: Landscape into Art, John Murray, Londres, 1945.

34 Max J. Friedländer: Landscape. Portrait. Still Life, trad. de R. F. C. Hull, Philosophical Library, Nueva York, 1949, p. 154.

35 Se trata de Das niederlandische Architekturbild, publicado en Halle, en 1908. 
(las discusiones no fueron estériles: se reconoció la existencia de la noveleta y del relato). Recientemente, en un trabajo sobre los orígenes del paisaje de ciudad holandés del siglo XVII, la historiadora soviética del arte I. A. Sokolova escribió lo siguiente:

Las tentativas de llegar a una opinión unánime acerca de cuándo un cuadro con una representación de una ciudad deja de ser un paisaje por completo y deviene una pura vista de ciudad, hasta ahora no se han visto coronadas por el éxito. Las proposiciones realizadas se han planteado como tarea separar ante todo ese tema de los dominios afines: el paisaje y la veduta. $3^{6}$

Los géneros pictóricos se caracterizan por su historicidad. Ésta se manifiesta de diversas maneras, pero se expresa sobre todo en el desarrollo interno de cada uno de ellos. Al tiempo que mantienen su continuidad histórica, los géneros sufren variaciones en el curso de su existencia, asumen formas distintas en diversos momentos de su "vida". Basta comparar los paisajes de los tiempos de Van Goyen, Ruisdael y Cuyp con los de la época de la Escuela de Barbizon, y éstos, a su vez, con los de fines del pasado siglo, para darse clara cuenta de lo dicho.

El desarrollo interno de los géneros, resultado de una incesante tensión entre elementos variantes e invariantes, está determinado por la acción que sobre él ejercen ininterrumpidamente las coyunturas externas: ante todo las corrientes pictóricas y la cambiante situación social. Por una parte, la transformación, la estructuración y la desestructuración de los géneros se efectúa por influjo del proceso histórico-pictórico en su conjunto, pero muy en especial por la acción de las aspiraciones filosóficas, cosmovisivas, sociales y culturales de las distintas corrientes pictóricas (sobre todo su visión del papel y funciones de la pintura), así como de sus aspiraciones específicamente pictóricas (sus principios creadores en cuanto a la relación obra-realidad extrapictórica, a la relación obra-receptores, y a las relaciones internas - composicionales y estilísticas - de la obra). Por otra, la variada gama de los factores sociales que, en diversos momentos históricos y con diversa fuerza, han influido en el desarrollo interno del paisaje, va desde el auge de una burguesía rica y poderosa en Holanda durante los siglos XVI y XVII, hasta los descubrimientos de la óptica y de la fisiología y la psicología de la percepción, a fines

36 I. A. Sokolova: "Istoki gollandskogo gorodskogo peisazha XVII veka", en Sovestkoe iskusstvoznanie 8o, Moscú, Sovetskii Judozhnik, núm. 2, 1981, p. 65. 
del pasado siglo; desde el desarrollo urbano y agroindustrial moderno hasta la invención de la fotografía en blanco y negro y en colores.

Para conocer a fondo una corriente pictórica, es importante establecer qué hizo ella con los géneros. Pero para conocer a fondo un género pictórico, es más que importante determinar cómo se comportó él bajo la acción de las distintas corrientes. Por ejemplo, ¿qué cambios provocó en el género "paisaje" la nueva coyuntura que fue el impresionismo? Dejando a un lado, por meras razones de tiempo, las importantes innovaciones relativas al espacio que tan certeramente ha señalado Francastel (relación forma-luz, triangulación del espacio, valores táctiles), rememoremos aquí aquella fugaz pero profunda observación de Lévi-Strauss sobre el impresionismo, formulada durante sus entrevistas con Charbonnier. Como se recordará, el relevante antropólogo francés, después de replicar que "no se puede considerar al impresionismo exclusivamente desde un punto de vista formal”, señaló:

Lo que me llama la atención de los impresionistas no es sólo el cambio de manera, sino el cambio de asunto: esta predilección repentina por los paisajes modestos de las afueras de las ciudades, los campos suburbanos y a menudo ingratos (...) una simple hilera de árboles, y me parece a mí que tenemos en esto una transformación considerable con relación a lo que no sólo Poussin, sino incluso los románticos entendían por "paisaje", y que debía ser un paisaje sublime con montañas, cascadas, árboles centenarios y así sucesivamente. 37

Pero la acción de las corrientes pictóricas sobre los géneros también se deja ver en otras expresiones, aún no mencionadas aquí, de la historicidad de los géneros. Nos referimos a la variación histórica de la jerarquía de los géneros y a la formación y desaparición de las variedades genéricas en el marco de éstos. Por razones de tiempo, examinaremos aquí sólo el primero de estos fenómenos.

Los géneros pictóricos no se desarrollan de manera uniforme: el género que en un período dado se halla en un primer plano y se muestra floreciente e influyente, en otra época puede pasar a ocupar un puesto secundario, marginal. Ya en su tiempo, Max Friedländer, tan penetrante observador como confuso ideólogo, se dio cuenta de las profundas diferencias existentes entre

37 Claude Lévi-Strauss: Arte, lenguaje, etnología. Entrevistas con George Charbonnier, trad. de F. González Aramburu, Instituto del Libro, La Habana, 1970, pp. 6566. Cf. Pierre Francastel: Études de sociologie de l'art, Denoël, París, 1970, pp. 201 y ss. 
la situación jerárquica de los géneros en los siglos pasados y aquella en que se hallaban en el momento en que escribía su clásico libro (por lo visto, en las primeras décadas de nuestro siglo). Señaló el historiador del arte:

Hubo un tiempo en que las categorías de la pintura entraban en algo así como una escala de valores, con el cuadro histórico y el cuadro devoto en la cima, el cuadro de género y el retrato más abajo, y la naturaleza muerta y el paisaje en el fondo. Este orden de rango se ha derrumbado. Se han hecho esfuerzos espasmódicos e infructuosos para resucitar el cuadro histórico y el devoto; el cuadro de género, divertido o lleno de sentimiento, es mirado con desconfianza. Hablando rigurosamente, lo que permanece como lo mejor y lo más altamente apreciado en el arte contemporáneo es el retrato o el grupo a la manera de retrato, la naturaleza muerta y el paisaje. $3^{8}$

Friedländer no ve la verdadera causa inmediata de ese fenómeno, no logra percibir tras él la dinámica de las corrientes pictóricas. Y es que cada corriente pictórica tiene un género (o grupo de géneros) preferido, privilegiado, en el que cree expresar de la mejor manera sus aspiraciones. Cada corriente establece una jerarquía: trata unos géneros como "mejores", "superiores", y a otros como "menores" y, en ocasiones, hasta como "despreciables"; cultiva ampliamente unos, aborda ocasionalmente otros, y no se ocupa en absoluto de unos terceros. Las corrientes que logran hacerse dominantes en un período, instauran en él su jerarquía de géneros. Cabe preguntarse, pues, qué significó el advenimiento y auge del impresionismo, por ejemplo, para la posición del paisaje en la jerarquía de los géneros. Significó su elevación a primerísimo plano, una exaltación a la que sólo la singular personalidad pictórica de Degas no se sumó. Pero, ¿qué ocurrió con el paisaje a la llegada triunfal del cubismo? Sencillamente que el cubismo, que situaba la naturaleza muerta en la cúspide de su jerarquía de géneros, privó al paisaje de su hegemonía, que, a decir verdad, resultó breve.

Como hemos dicho ya, el paisaje como género es un conjunto o sistema de convenciones históricamente variable. En determinadas culturas y períodos históricos, el convencionalismo del paisaje asume dimensiones extraordinarias: por una parte, casi todos los elementos de la obra —-temáticos, composi-

38 Max J. Friedländer: Landscape..., ob. cit., p. 11. (Desconocemos la fecha exacta de aparición del original en alemán.) 
cionales, estilísticos - son sometidos a una minuciosa convencionalización; y, por otra, en la recepción social el valor estético de la nueva obra individual no está determinado por la originalidad de la misma, sino por la fidelidad con que ella observa las convenciones del género (en el mejor de los casos, no por la exactitud con que imita obras-modelos precedentes, sino por la habilidad con que "improvisa" dentro del más estricto respeto a las convenciones genéricas).

El pintor y paisajista chino Chiang Yee ha subrayado que en su país de origen el género paisajístico se caracteriza por un gran número de convenciones: "ciertos colores para indicar ciertas distancias, ciertas formas para el mismo propósito, ciertos movimientos para mostrar ciertas reacciones naturales, cierto tratamiento para octubre, para marzo"39 Refiriéndose al convencionalismo en el plano temático, Yee nos asegura que todos los paisajes chinos representan "montañas y agua en alguna forma", y nos revela el elocuente hecho de que el término chino que designa el género paisajístico, Shan- shui, significa literalmente: "montaña y torrente". Pero aún más ilustrativas de la amplitud que puede cobrar la convencionalización del paisaje, son unas líneas en las que el pintor Wang Wei, de la dinastía Tang (618-905 d.n.e.), formula algunos de los muchos lineamientos que, según Yee, han venido cumpliéndose en la práctica pictórica hasta el presente siglo:

Cuando pintes paisajes (...) concede diez pies a las montañas, un pie a los árboles, una pulgada a los caballos y un décimo de pulgada a las figuras humanas (...) Las nubes cubren la mitad de las montañas, las cascadas cubren parte de las rocas, los árboles cubren las torres y los pabellones, y las figuras humanas cubren los caminos (...) éstos son los métodos de la pintura. Una escena matutina es representada por mil montañas que brillan en el alba con ligeras neblinas, y un atardecer se logra mostrando el sol poniente detrás de las montañas. $4^{\circ}$

Se podría pensar que este convencionalismo extremo tiene algo de específicamente "asiático", pero basta profundizar un poco en la historia del paisaje occidental para descubrir numerosas situaciones análogas en diversos períodos de ésta. Veamos, por ejemplo, la precisa descripción que nos ha dado Gombrich de la situación en que encontró Constable el paisaje de su tiempo:

39 Chiang Yee: The Chinese Eye. An Interpretation of Chinese Painting, $\mathbf{2}^{\mathrm{a}}$ ed., Indiana University Press, Bloomington y Londres, 1970, p. 163.

40 Citado según Chiang Yee: ob. cit., pp. 162-163. 
Los paisajistas elegantes que seguían tomando a Claudio por modelo, pusieron en juego un gran número de recursos, con ayuda de los cuales cualquier aficionado podía componer un verdadero cuadro sumamente agradable. Un árbol sugestivo en el primer término serviría como violento contraste de las distantes perspectivas que se abrían sobre la parte central. Las gamas de color se elaboraban primorosamente. Los colores calientes, con preferencia las tonalidades pardas y doradas, debían estar en el primer término; los fondos debían diluirse en tintas de azul pálido. Existían recetas para pintar las nubes, y recursos especiales para reproducir las cortezas de los robles nudosos. ${ }^{41}$

En cambio, el arte moderno occidental se ha caracterizado por la relativa constancia de su lucha, tan encarnizada como infructuosa, contra las convenciones. Eco ha presentado ese fenómeno desde el punto de vista de la teoría semiótico-informacional: "la invención de un código inédito, obra por obra (a lo sumo, serie de obras por serie de obras del mismo autor), sigue siendo una de las constantes del arte contemporáneo". $4^{2} \mathrm{Y}$ es que las tendencias más extremistas de la vanguardia de los años 10-30 y de la neovanguardia de los años 6o-70 hicieron renacer en nuestro siglo lo que Hauser, refiriéndose al romanticismo, llamó: "una de las convenciones más paralizadoras de todos los tiempos: el principio de la espontaneidad a toda costa", la "convención de la ausencia de convenciones".43 Sin embargo, tal como ocurrió con el romanticismo, las innovaciones de la vanguardia se convencionalizaron en mayor o menor medida, con mayor o menor rapidez: he ahí la amplia producción de lo que, con toda razón, el historiador húngaro del arte, Miklós Szabolcsi, ha llamado la "seudovanguardia de los años cincuenta”,44 o, más en particular, el destino del surrealismo, movimiento que inicialmente se dio a conocer como el más radical propugnador de la "revolución permanente" en el arte y que, como ya en 1949 señalaba Carpentier en su prólogo a El reino de este mundo, terminó convirtiéndose en un repertorio burocrático de "fórmulas consabidas", “códigos de lo fantástico, basados en el principio del burro devorado por un higo". Análoga parece ser la suerte de la neovanguardia en nuestros días, y,

41 E. H. Gombrich: Historia del arte, Argos, Barcelona, 1951, p. 391.

42 Umberto Eco: La struttura assente, Bompiani, Milán, 1968, p. 163.

43 Arnold Hauser: Introducción a la historia del arte, Instituto del Libro, La Habana, 1969, p. 466.

44 Miklós Szabolcsi: “A neoavantgarde”, en A neoavantgarde, Gondolat, Budapest, 1981, p. 27. 
probablemente, pronto se hablará de la "seudoneovanguardia" de mediados de los años 70 en adelante.

La naturaleza muerta, el paisaje y el retrato - los tres géneros artísticos tradicionales que habían logrado sobrevivir a la indiferencia o el rechazo de los autores de vanguardia (los cubistas, con su afición a la naturaleza muerta, fueron una de las pocas excepciones) y que agonizaban en medio de la hegemonía abstracta de los años de posguerra-, no resistieron el empuje de las corrientes de neovanguardia, con su total abandono de las calificaciones genológicas. Tal vez más exacto sería decir: con su desprecio hacia las convenciones genéricas tradicionales y su afán de crear algo así como nuevos "géneros personales": los "embalajes" de Christo, las "compresiones" y "expansiones" de Cesar, los "móviles" de Calder, las "acumulaciones" y "cóleras" de Arman, etc. En el terreno de la pintura en particular, la conciencia genérica quedó restringida a las obras del pasado, y en la práctica creadora perdieron todo vestigio de vigencia las convenciones del paisaje, la naturaleza muerta, el retrato, etc. Si en algún cuadro se les daba entrada a esas convenciones, era sólo para parodiarlas o simplemente para "citarlas": recuérdense los paisajes con arquitectura y las marinas de Lichtenstein. Si todavía en 1963 la redacción de la afamada revista Connaissance des Arts podía realizar una encuesta con el título “'Tiene aún su puesto el paisaje en la pintura actual?”, unos años más tarde tal pregunta hubiera parecido un despropósito. Entre otras cosas, porque ni prosperaron las tendencias abstractas que, en su evolución hacia un "naturalismo imaginario", harían renacer el paisaje en la forma de un "impresionismo interior", ni cobró fuerza en la conciencia pictórica de la época la "lectura paisajística" que hallaba "cierta equivalencia plástica, trascendida, de un efecto de naturaleza" en variadas obras de la abstracción lírica o informal. ${ }^{45}$ Por lo demás, es preciso señalar que, en general, la relación de la

45 “Le paysage a-t-il encore sa place dans la peinture actuelle?", en Connaissance des Arts, París, febrero de 1963 (véanse en particular las respuestas de Henry Galy-Charles y François Mathey en las pp. 73 y 75, respectivamente). Ya por 1946, Mukarovský habló de la posible lectura de ciertos cuadros abstractos como "alusiones a determinadas realidades", y señaló, como ejemplo, que una mancha de color azul celeste, si estaba situada en la parte superior de la superficie de un cuadro abstracto, podía devenir portadora del significado "cielo" — o del significado "superficie del agua", si se hallaba en la parte inferior de aquélla- (“O strukturalismu”, en J. M.: Studie z estetiky, $2^{\mathrm{a}}$ ed., Odeon, Praga, 1971, pp. 152-153). Por su parte, en 1958, Ingarden también habló de cuadros de tendencia abstracta ante los cuales uno empieza a ver involuntariamente "ciertas cosas inusuales (algo así 'como si' fueran flores, plantas, piedras, etc.)", pero subrayó que en ese caso se trata de cierta especie de "carácter semiabstracto" del cua- 
neovanguardia con la Naturaleza y sus escenarios no tendió a establecerse en el plano de la representación pictórica, icónico-mimética, sino por las inusitadas vías del land art (Dibbets, De Maria), del earth art (Heizer, Smithson) y de aquellos cuadros "cosmogónicos" de Yves Klein que consistían en las huellas dejadas sobre la superficie del lienzo por el viento o la lluvia.

Se podría escribir una historia del paisaje como historia de la constitución y cambio de las convenciones del género. Tal historia debería tener en cuenta, sin falta, todo lo escrito por Hauser, Gombrich y Lotman sobre las convenciones artísticas. Creemos necesario subrayar aquí dos ideas claves que prevendrían al historiador contra el peligro del gnoseologismo vulgar, al que tan dados son, todavía hoy, muchos investigadores marxistas: la afirmación de Gombrich de que "la verdad de un paisaje es relativa, y tanto más, cuanto más se atreve el artista a aceptar el reto de la luz",46 y la advertencia de Lotman y Uspenski de que "la convencionalidad no puede ser limitada a tales o cuales obras de arte", de que "contraponer arte convencional y arte realista [...] es teóricamente ilícito". 47

Desde el punto de vista de la semiótica, el paisaje y los demás géneros pictóricos deben ser considerados como códigos, como "lenguajes". Sin embargo, al realizar su clasificación de los códigos que intervienen en la comunicación visual, Umberto Eco mencionó diez clases de códigos (perceptivos, de reconocimiento, de transmisión, tonales, icónicos, iconográficos, del gusto y de la sensibilidad, retóricos, estilísticos, y del inconsciente), excluyendo de su enumeración los códigos genéricos o genológicos. ${ }^{48}$ Tras esta injustificable omisión vemos la influencia de un hecho antes mencionado: la casi total inexistencia de una conciencia genológica activa en los sectores más elitarios de pintores y conocedores de los países desarrollados occidentales. Explicamos así esta omisión por la sencilla razón de que, cuando Eco aborda en particular la comunicación arquitectónica (en la que hoy día sigue ha-

dro, que puede hasta tener ciertos encantos, pero, a pesar de eso, hace que el cuadro deje de ser abstracto sensu stricto" (“O tak zwanym malarstwie abstrakcyjnim”, en R. I.: Studia z estetyki, PWN, Varsovia, 1970, t. 3, p. 196).

46 E. H. Gombrich: Art and illusion, Phaidon Press, Londres, 1972, p. 41.

47 Iu. M. Lotman y B. Uspenski: “USLOVNOST' v iskusstve”, en Filosofskaia entsiklopediia, Sovetskaia Entsiklopediia, Moscú, 1970, t. 5, p. 288.

48 Umberto Eco: La struttura assente, ed. cit., pp. 145-148. Más adelante (pp. 160-161), al referirse a las configuraciones visuales anicónicas de la pintura abstractageométrica y abstracta-informal, Eco menciona otras dos clases de códigos: los matemático-geométricos y los microfísicos. 
ciéndose sentir una conciencia genológica), no deja de incluir en su clasificación de los códigos arquitectónicos una variedad de códigos semánticos que él denomina "géneros tipológicos".49 A estos géneros o códigos tipológicos, que nos dicen, por ejemplo, "cómo debe estar hecha una iglesia para ser una “iglesia”, él los divide en "tipos sociales" (hospital, villa, escuela, castillo, etc.) y "tipos espaciales" (templo de planta redonda, laberinto, etc.). Y hay que reconocer - quiéralo Eco o no-que la "articulación en géneros tipológicos" es un modo de codificación semántica que también existe en la pintura de distintas épocas. La presentación de un cuadro como paisaje introduce esa obra en la serie de los cuadros-paisajes. Para leer de manera integral el significado de ese cuadro, es preciso examinarlo como un elemento de esa serie, un elemento que entra en relaciones significativas de oposición o semejanza con otros elementos de la serie. La interpretación de las obras paisajísticas individuales no puede prescindir de los valores semánticos que aporta la lectura de éstas en el esencial contexto genológico.

La semiótica del paisaje, el estudio de los aspectos semánticos, sintácticos y pragmáticos del "lenguaje paisajístico", deberá abordar múltiples cuestiones: unas tan generales como la de los mecanismos metafóricos y metonímicos en la constitución del significado del paisaje, y otras tan particulares como el "efecto de extrañamiento" señalado por Brecht en ciertos cuadros de Breughel el Viejo, en los que aparecen un paisaje flamenco en un macizo de los Alpes o contemporáneos flamencos del pintor en un paisaje antiguo y sureño. ${ }^{0}$

Pero una poética del paisaje no podría ser construida exclusivamente en términos semióticos. Afirmamos esto no porque creamos que la semiótica sólo puede ocuparse de la sincronía o de las estructuras, en respectivo detrimento del conocimiento de la diacronía y las funciones (tales prejuicios sólo pueden basarse en lecturas limitadas a ciertos autores occidentales), sino porque la semiótica no puede ocuparse ella misma de la dimensión estrictamente sociológica que debe tener la poética de todo género pictórico - $-\mathrm{y}$ no puede hacerlo, sencillamente, porque esa dimensión no entra en el objeto de investigación que la define como ciencia independiente, sino en el de la sociología. Así pues, la poética del paisaje no debe ser sólo semiótica, sino tam-

49 Ibíd., p. 224.

50 Bertolt Brecht: "Verfremdungseffekt in der erzählenden Bildern des älteren Breughel”, en B. B.: Schriften zur Literatur und Kunst, Aufbau Verlag, Berlín y Weimar, 1966, t. 1, pp. 345-348. 
bién sociológica. Es decir, deberá generar no sólo trabajos como el reciente de Marc Eli Blanchard sobre la naturaleza muerta, ${ }^{51}$ sino también otros como el de Antonio Banfi sobre el mismo tema. ${ }^{52}$ Y más aún, deberá producir trabajos en los que se conjuguen ambas perspectivas.

(Consideramos que el término "poética", por su etimología — del griego poietikós: "creador, relativo a la creación”-, resulta aplicable no sólo en la ciencia literaria, sino también en el estudio científico de las demás artes.)

Esa poética del paisaje, que habría de ser histórica hasta cuando fuera teórica, no podría estar desvinculada de la realidad viviente de la pintura de su tiempo. A ella tendrán que interesarle - como problemas, y no en calidad de ilustraciones - fenómenos tan apasionantes como el cambio de la noción del paisaje a que asistimos hoy en nuestro país. Hace exactamente veinticinco años - es decir, un año y algunos meses antes del triunfo revolucionario-, una entidad cubana organizó una Exposición de Paisajes Cubanos y la presentó en España. ¿Qué concepto del paisaje se hallaba implícito en esa muestra? La respuesta a esta interrogante la hallaremos en el texto de la conferencia que, con motivo de esa exposición, leyó en el Círculo de Bellas Artes de Madrid, el 22 de octubre de 1957, un ilustrado ideólogo de la burguesía nacional cubana, el conocido ensayista Jorge Mañach. En esa conferencia, titulada Paisaje y pintura en Cuba, el paisaje es concebido como "traslado fiel" de "lo que está en el sobrehaz de las cosas como fisonomía o cariz familiar de ellas, lo que realmente vemos todos los días o podemos toparnos alguna vez al paso".53 En la muestra no hubo una sola obra de los no naturalistas Lam, Portocarrero, Amelia, Mariano o Abela. Su presencia en ella, por lo demás, habría sido inconsecuente con esa definición. Así, si determinado cuadro no reproducía de manera "más o menos literal" la exterioridad visual de los escenarios naturales, si en él - a través de abstracciones o de alusiones - se comunicaban aspectos "esenciales" y no "aparenciales" de la naturaleza, ese cuadro no era un paisaje. Para Mañach — que no era partidario del naturalismo o el academicismo y que reconocía que en la pintura de Lam y demás autores mencionados es

51 Marc Eli Blanchard: "On Still Life", en Yale French Studies, New Haven, núm. 61, 1981. Allí anuncia el autor la próxima aparición de su artículo "Natures mortes: pour une théorie de la désignation en peinture", en Communications, 1981.

52 Antonio Banfi: "La naturaleza muerta", en A. B.: Filosofía del arte, Ediciones ICAIC, La Habana, 1967.

53 Jorge Mañach: Paisaje y pintura en Cuba (conferencia leída en el Círculo de Bellas Artes de Madrid, el 22 de octubre de 1957, con motivo de una Exposición de Paisajes Cubanos), Madrid, 1957, p. 17. 
"donde se da lo cubano en su forma más esenciada"-,54 eso implicaba que el paisaje era un género menor y hasta casi un género de actividad cultural extraartística, cuyas obras no debían ser vistas y juzgadas ante todo como obras específicamente artísticas, sino como "fotografías" o documentos geográficos o ecográficos. A fin de que no se le pidiera otra cosa a "estos artistas modestos de nuestra exposición", él mismo aclaraba: "A muchos de esos paisajes no les falta oficio ni gracia. A todos los salva — si también en arte el amor es vía de salvación - la fidelidad con que dan testimonio de nuestra tierra. Quiero decir que esta exposición vale sobre todo - y así creo que debemos mirarla - como un documento más o menos literal de algunos aspectos cubanos."55 Entre esos "aspectos cubanos" fielmente testimoniados no estarían, seguramente, la explotación, la miseria, el hambre y la desocupación que reinaban por doquier en el paisaje cubano, sino sólo aquellas apariencias geográficas, ecográficas y etnográficas que le permitían a cierta burguesía nacional ver el paisaje cubano como un entrañable traspatio criollo bucólico y a los turistas extranjeros contemplarlo como un exótico paraíso tropical. En todo caso, aquellos cuadros se prestaban para la propaganda turística capitalista: la Exposición de Paisajes Cubanos fue organizada y llevada a España por la Compañía Cubana de Aviación con el propósito - reconocido hasta por el conferenciante- de promover el turismo español hacia Cuba.

Un cuarto de siglo más tarde, el Salón de Paisaje (ya en su segunda edición) organizado por la Dirección de Artes Plásticas del Ministerio de Cultura de la Cuba revolucionaria, nos coloca ante una concepción radicalmente distinta del género: en esta muestra no sólo han sido incluidas obras no naturalistas de Portocarrero, Mariano y otros grandes pintores cubanos ausentes en aquella exposición prerrevolucionaria, sino que se le ha dado cabida a gran cantidad de obras (la abrumadora mayoría de las expuestas) que se relacionan con la naturaleza por las más diversas vías no "literales": desde el surrealismo hasta el conceptualismo. Este Salón expresa o propone, pues, una nueva noción del paisaje, que no lo aísla de las búsquedas contemporáneas del arte; que, por el contrario, lo inserta de lleno en la lucha del creador moderno contra las convenciones artísticamente agotadas y en su constante creación y exploración de otras que podrían corresponder mejor a nuestros días; y que, en fin,

54 Jorge Mañach: Paisaje y pintura en Cuba (conferencia leída en el Círculo de Bellas Artes de Madrid, el 22 de octubre de 1957, con motivo de una Exposición de Paisajes Cubanos), Madrid, 1957, p. 17.

55 Ibíd., p. 18. 
no lo ve como un enclave "modesto", marginal, cuya existencia es tolerable y hasta propiciable no tanto en calidad de género específicamente artístico, sino sobre todo como fuente de "fotos topográficas al pincel".

Si esta noción propuesta por el Salón expresa ya una nueva conciencia genérica de los creadores respecto a las obras de su presente, o si sólo viene a confirmarla, es cuestión que sólo una investigación minuciosa podría determinar. He ahí, pues, un buen tema actual para esa necesaria poética del paisaje, a cuyo desarrollo hemos querido contribuir con estas líneas. 